\title{
Identification of Sounds of Ancient Scripts
}

\author{
Bhaskaran Sumathy Manoj \\ Professor, Department of Pulmonary Medicine \\ Late Baliram Kashyap Memorial Government Medical College \\ Jagdalpur, District: Bastar, Chhattisgarh, Pin Code - 494001, \\ India
}

\begin{abstract}
This work confirms the empirical assumption that there is a relation between images of ancient script characters, their sounds, related tongue tip movements and tongue contours. This relation is used to identify sounds of undeciphered scripts. As a first step, sounds which are not in combinations are selected from Hindi, English and Tamil. There are 24 such sounds. These sounds are then represented by points on inner surface of the oral cavity. Images of characters of Egyptian hieroglyphs and Linear B scripts, which have already been deciphered, are selected and their corresponding sounds are studied to precisely position 24 sounds in the vocal cavity. Then, the relation between images, sounds, tongue tip movements and tongue contours is also verified. Using this information, Indus script and Oracle bone scripts are analyzed and their sound values are identified. This approach may be of help in identifying sounds of ancient scripts representing images and as well as understanding primitive spoken languages lacking written scripts.
\end{abstract}

Keywords: Indus valley script, oracle bone valley script, decipher ancient scripts, script image differentiator

\section{Introduction}

Ancient scripts can be considered as early form of information technology ${ }^{10}$ in the world. The image characters of these scripts mostly depict pictures of living creatures and their activities along with nature. Ancient scripts have been discovered in different regions of the world. The most ancient script discovered till date is Egyptian Hieroglyph. It was used close to 3000 B.C ${ }^{12}$. Before 1819, Thomas Young, a British polymath, attempted to understand the Egyptian hieroglyphs. In 1822, Jean-Francois Champollion, an Orientalist, deciphered Egyptian Hieroglyphs ${ }^{13}$. There are other ancient scripts which too were deciphered over a period of time. Linear B from Mycenaean civilization was deciphered by Michael Ventris in $1952^{11}$. But, there are still many such ancient scripts, which are yet to be understood such as Indus valley script and the Oracle bone script of Asia.

The present effort has two objectives -

- Confirm the empirical assumption that there exists relation between (1) images of ancient scripts, (2) corresponding sounds and the (3) tongue contours and (4) tongue tip movements involved while verbalizing the sounds. Egyptian \& Linear B scripts are used to confirm the empirical assumption.

- Use the results obtained above, to identify sounds of some characters in Indus and Oracle bone scripts The work was conducted solely by me, from December 2005 to June 2019 unaided by any form of external support and nor is it sponsored.

\section{Methods}

In this study, the following ancient scripts are used:

- Egyptian Hieroglyphs $\mathrm{s}^{2,3,4,5,6}$

- Linear $\mathrm{B}^{7}$

- Indus valley script ${ }^{8}$

- Oracle bone script ${ }^{9}$

This section describes the following steps:

1. Map points in oral cavity touched by tongue tip and contours observed on the externally observable surface of the tongue, while verbalizing unmixed sounds.

2. Then the tongue contours related to verbalized unmixed sounds, mapped above, in the oral cavity are matched with tongue contours generated by sounds of deciphered scripts-Egyptian and Linear B scripts.

3. Tongue contours of matched unmixed sounds from Step 1 are further matched with contours of related images of characters belonging to Egyptian and Linear B scripts, for precise positioning of unmixed sounds. 
4. Verify next part of the correlation by (i) reproducing the complete image or the image of differentiating part of the character used for analysis using bulges and depressions of the resultant sound and (ii) comparing tongue tip movements while verbalizing sounds obtained from Step 3 with images of same characters.

5. Use the above mentioned correlation to identify sounds of ancient undeciphered scripts.

2.1 Map tongue tip movements and tongue contours while verbalizing unmixed sounds to points in Vocal Circle

- 24 unmixed sounds or monosyllables that are not made up of other sounds are chosen from English, Hindi and Tamil. English is a widely spoken language in the world and Hindi is widely spoken in a highly populous nation like India followed by Pakistan. Tamil is spoken in certain parts of India and Sri Lanka.

- While verbalizing above sounds, tongue tip touches various points in the oral cavity referred to as vocal circle (Refer to Figure 1) because of the stress on its functional aspect.

- All 24 points touched by tongue tip on verbalizing above sounds in various combinations are arranged on vocal circle. Let us take sounds Tha \& Zha as an example. Various sound combinations (pairs of sounds) involving Tha have been analyzed. Here we discuss the combination ThaZha. When Tha is pronounced, the tongue tip touches a point near the Lip Side, say point $X$, in the upper vocal circle. Then when Zha is pronounced, the tongue tip touches a point behind (towards the throat side) point X. Let us call this point Y. A similar exercise is done for various combinations of the 24 unmixed sounds. Thus, all 24 unmixed sounds are mapped on various points on the vocal circle.

Figure 1 - Representation of unmixed or basic sounds VOCAL CIRCLE (V.C).

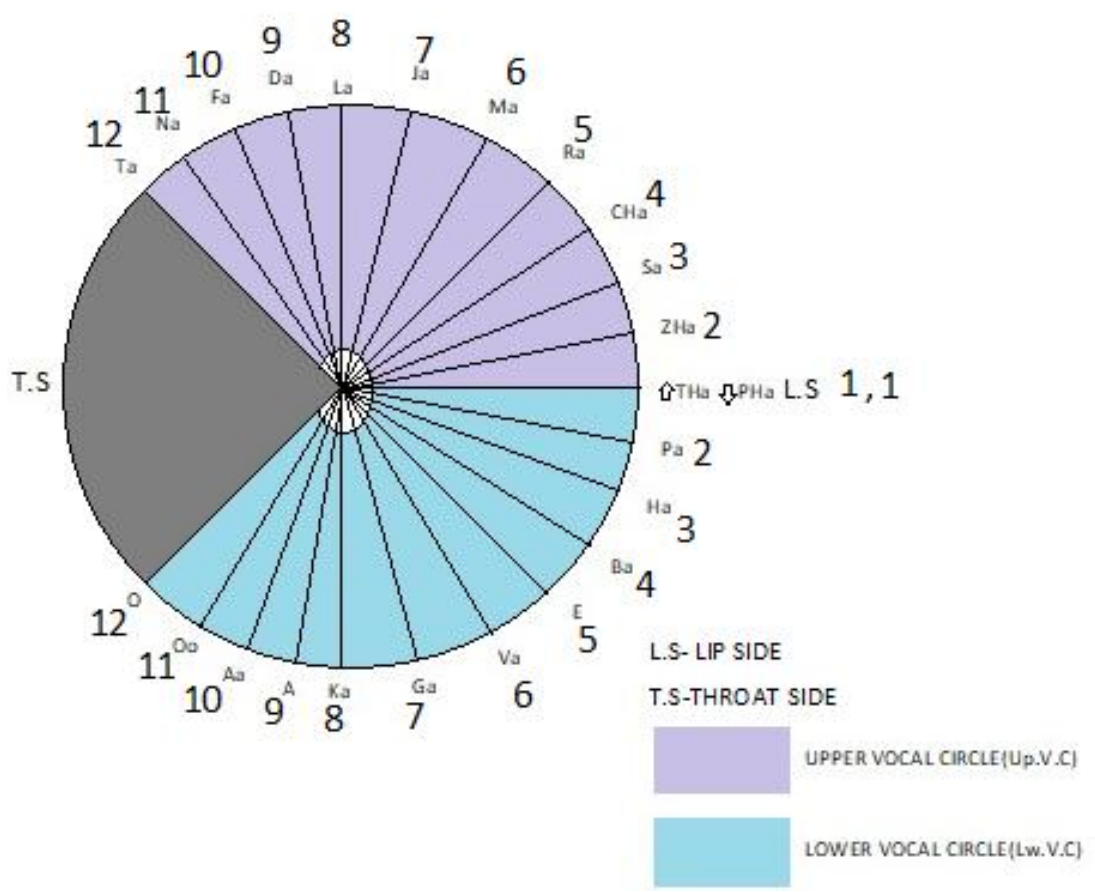

- So, 12 points are found (see Figure 1) in the upper part of the vocal circle beginning from the junction of both upper \& lower pair of central incisor teeth till back of the vocal circle. Similarly, 12 points are found in the lower part of the vocal circle. But, unmixed sound Tha positioned at 1, is in fact at the level of lower part of upper central incisors. Similarly the unmixed sound PHa positioned at 1, is at the level of upper part of lower central incisors. For the ease of representation, positions of 1 in both upper and lower part are considered as single i.e. at the junction between both upper and lower central incisors. However, to discriminate positions of THa \& PHa at position 1 from each other, respective B \& D need to be taken into account (Refer to Table 1 \& Table 2).

- The numbering of the points is done starting from Lip side (see Figure 1) towards the Throat side. For example, THa is at point $1 \& \mathbf{T a}$ is at point 12 in the upper part of the vocal circle.

- Lip side contains points bearing numbers $<8$ and Throat side contains points bearing numbers $>8$. The reason for creating such an arrangement is for the ease of analysis.

\subsubsection{Bulges and Depressions (B \& D) of Tongue Contours}


Other than the movements of tongue tips, the contour of the tongue is also observed while pronouncing 24 sounds. Tongue contour is described in terms of a bulge and a depression. The centre of a bulge (convexity) and a depression (concavity) on the visible surface of the tongue face two numbered points in the vocal cavity. These points (B \& D) are referred to by their assigned numbers as discussed earlier.

\subsubsection{Sounds in Lower vocal circle (Lw.V.C )}

There are 12 Basic or unmixed sounds positioned from lip side (L.S) to throat side (T.S). While pronouncing these sounds, the tongue tip touches different points in the lower vocal circle. The tongue contours, while pronouncing these sounds, are also observed and the position of the respective centres of bulge and depression on the visible surface of the tongue are noted. These two centres face two positions on the Upper Vocal Circle. The numbers of the points on the Upper Vocal Circle are used to describe the sound.

For example, when sound $\mathrm{E}$ is pronounced as part of the sound combination $\mathrm{E}-\mathrm{V}$ or $\mathrm{V}-\mathrm{E}$, the centre of the bulge of the tongue is found to be facing point 8 in Upper Vocal Circle and centre of the depression on the tongue is found be facing point 5 on the Upper Vocal Circle. So, B \& D associated with sound E is represented as 8B/5D.

The above approach is used to describe all the 12 unmixed sounds in Lower Vocal Circle. It should be noted that B + D is always 13. Most of the sounds in the Table 1 are pronounced as in Standard English. The unmixed sound "A" (at position number 9) is pronounced as in "Mate" in English. The sound "Aa" (at position number 10) is pronounced as in "Fat". PHa (at position number 1) is pronounced as "Pa" (at the beginning) with slight stress on "Ha" at the end (with apposed lips suddenly opening). Character $\bar{T}$ in Hindi represents PHa. Whereas, character $\bar{\cdot}$ with a dot (nuktha) represents "Fa" in Hindi . PHa and $\mathrm{Pa}$ are almost similar in pronunciation. The addition of PHa results in ensuring that the total sounds in Lower Vocal Circle is 12. This matches with the total number of sounds in Upper Vocal Circle. This symmetry facilitates easier numbering of B \& D of unmixed sounds. The sounds that are represented by upper case letters with "a" as suffix is pronounced as in the English word - "similar". But, the sound "a" is relatively short and silent.

Table 1 - B \& D corresponding to basic sounds of Lower Vocal Circle

\begin{tabular}{|c|c|c|}
\hline $\begin{array}{l}\text { Basic/Unmixed } \\
\text { Sound }\end{array}$ & $\begin{array}{l}\text { Related } \\
\text { Combination } \\
\text { of sounds }\end{array}$ & B \& D Description \\
\hline $\mathrm{PHa}$ & $P H-P, P-P H$ & $\begin{array}{l}\text { B12-Centre of the bulge facing point } 12 \text { in Upper Vocal circle. } \\
\text { D1-Centre of the depression facing point } 1 \text { in Upper Vocal circle }\end{array}$ \\
\hline $\mathrm{Pa}$ & $P-H, H-P$ & $\begin{array}{l}\text { B11-Centre of the bulge facing point } 11 \text { in Upper Vocal circle. } \\
\text { D2-Centre of the depression facing point } 2 \text { in Upper Vocal circle }\end{array}$ \\
\hline $\mathrm{Ha}$ & $H-B, B-H$ & $\begin{array}{l}\text { B10-Centre of the bulge facing point } 10 \text { in Upper Vocal circle. } \\
\text { D3-Centre of the depression facing point } 3 \text { in Upper Vocal circle }\end{array}$ \\
\hline $\mathrm{Ba}$ & $B-E, E-B$ & $\begin{array}{l}\text { B9- Centre of the bulge facing point } 9 \text { in Upper Vocal circle. } \\
\text { D4-Centre of the depression facing point } 5 \text { in Upper Vocal circle }\end{array}$ \\
\hline $\mathrm{E}$ & $E-V, V-E$ & $\begin{array}{l}\text { B8-Centre of the bulge facing point } 8 \text { in Upper Vocal circle. } \\
\text { D5-Centre of the depression facing point } 5 \text { in Upper Vocal circle }\end{array}$ \\
\hline $\mathrm{Va}$ & $V-G, G-V$ & $\begin{array}{l}\text { B7- Centre of the bulge facing point } 7 \text { in Upper Vocal circle. } \\
\text { D6-Centre of the depression facing point } 6 \text { in Upper Vocal circle }\end{array}$ \\
\hline $\mathrm{Ga}$ & $G-K, K-G$ & $\begin{array}{l}\text { B6- Centre of the bulge facing point } 6 \text { in Upper Vocal circle. } \\
\text { D7-Centre of the depression facing point } 7 \text { in Upper Vocal circle } \\
\text { Note: G is pronounced as in "Gum" }\end{array}$ \\
\hline $\mathrm{Ka}$ & $K-A, A-K$ & $\begin{array}{l}\text { B5-Centre of the bulge facing point } 5 \text { in Upper Vocal circle. } \\
\text { D8-Centre of the depression facing point } 8 \text { in Upper Vocal circle }\end{array}$ \\
\hline A & $A-A a, A a-A$ & $\begin{array}{l}\text { B4- Centre of the bulge facing point } 4 \text { in Upper Vocal circle. } \\
\text { D9-Centre of the depression facing point } 9 \text { in Upper Vocal circle }\end{array}$ \\
\hline
\end{tabular}




\begin{tabular}{|l|l|l|}
\hline $\begin{array}{l}\text { Basic/Unmixed } \\
\text { Sound }\end{array}$ & $\begin{array}{l}\text { Related } \\
\text { Combination } \\
\text { of sounds }\end{array}$ & B \& D Description \\
\hline Aa & $\begin{array}{l}\text { Aa-Oo, Oo- } \\
\text { Aa }\end{array}$ & $\begin{array}{l}\text { B3- Centre of the bulge facing point 3 in Upper Vocal circle. } \\
\text { D10-Centre of the depression facing point 10 in Upper Vocal } \\
\text { circle. Note: Aa is pronounced as in "Apple" }\end{array}$ \\
\hline Oo & Oo-O, O-Oo & $\begin{array}{l}\text { B2- Centre of the bulge facing point 3 in Upper Vocal circle. } \\
\text { D11-Centre of the depression facing point 11 in Upper Vocal } \\
\text { circle. Note: Oo is pronounced as in "Cool" }\end{array}$ \\
\hline O & $\begin{array}{l}\text { B1- Centre of the bulge facing point 1 in Upper Vocal circle. } \\
\text { D12-Centre of the depression facing point 12 in Upper Vocal } \\
\text { circle. Note: O is pronounced as in "Old" }\end{array}$ \\
\hline
\end{tabular}

\subsubsection{Sounds in Upper Vocal Circle (Up.V.C)}

There are 12 Basic or unmixed sounds positioned from lip side (L.S) to throat side (T.S). While pronouncing these sounds, the tongue tip touches different points in the Upper Vocal Circle. The tongue contours, while pronouncing these sounds, are also observed and the position of the respective centres of bulge and depression on the visible surface of the tongue are noted. These two centres face two positions on the Lower Vocal Circle. The numbers of the points on the Lower Vocal Circle are used to describe the sound.

The above approach is used to describe all the 12 unmixed sounds in Upper Vocal Circle. It should be noted that B + D is always 13 .

Most of the sounds in the Table 2 are pronounced as in Standard English. The unmixed sound ZHa at position 2 , is spoken as ZHa in English. In Tamil, ZHa is represented by the character- $\&$. The sounds that that are represented by upper case letters with "a" as suffix are pronounced as in the English word - "similar". But, the sound "a" is relatively short and silent.

Table 2 - B \& D corresponding to basic sounds of Upper Vocal Circle

\begin{tabular}{|c|c|c|}
\hline $\begin{array}{l}\text { Basic/Unmixed } \\
\text { Sound }\end{array}$ & $\begin{array}{l}\text { Related } \\
\text { Combination } \\
\text { of sounds }\end{array}$ & B \& D Description \\
\hline THa & $T H-\mathrm{ZH}$ & $\begin{array}{l}\text { B12-Centre of the bulge facing point } 12 \text { in Lower Vocal circle. } \\
\text { D1-Centre of the depression facing point } 1 \text { in Lower Vocal circle }\end{array}$ \\
\hline $\mathrm{ZHa}$ & $\mathrm{ZHa}-\mathrm{S}, \mathrm{S}-\mathrm{ZHa}$ & $\begin{array}{l}\text { B11- Centre of the bulge facing point } 11 \text { in Lower Vocal circle. } \\
\text { D2-Centre of the depression facing point } 2 \text { in Lower Vocal circle } \\
\text { Note: ZHa is pronounced as in "ZHa" as in English. }\end{array}$ \\
\hline $\mathrm{Sa}$ & $\mathrm{S}-\mathrm{CH}$ & $\begin{array}{l}\text { B10-Centre of the bulge facing point } 10 \text { in Lower Vocal circle. } \\
\text { D2-Centre of the depression facing point } 2 \text { in Lower Vocal circle }\end{array}$ \\
\hline $\mathrm{CHa}$ & $\mathrm{CH}-\mathrm{R}$ & $\begin{array}{l}\text { B9-Centre of the bulge facing point } 9 \text { in Lower Vocal circle. } \\
\text { D3-Centre of the depression facing point } 3 \text { in Lower Vocal circle }\end{array}$ \\
\hline $\mathrm{Ra}$ & $R-M, M-R$ & $\begin{array}{l}\text { B8-Centre of the bulge facing point } 8 \text { in Lower Vocal circle. } \\
\text { D4-Centre of the depression facing point } 4 \text { in Lower Vocal circle }\end{array}$ \\
\hline $\mathrm{Ma}$ & $M-J, J-M$ & $\begin{array}{l}\text { B7-Centre of the bulge facing point } 7 \text { in Lower Vocal circle. } \\
\text { D5-Centre of the depression facing point } 5 \text { in Lower Vocal circle }\end{array}$ \\
\hline $\mathrm{Ja}$ & $J-L, L-J$ & B6- Centre of the bulge facing point 6 in Lower Vocal circle. \\
\hline
\end{tabular}




\begin{tabular}{|l|l|l|}
\hline & & D7-Centre of the depression facing point 7 in Lower Vocal circle \\
\hline La & $L-D, D-L$ & $\begin{array}{l}\text { B5-Centre of the bulge facing point 5 in Lower Vocal circle. } \\
\text { D8-Centre of the depression facing point } 8 \text { in Lower Vocal circle }\end{array}$ \\
\hline $\mathrm{Da}$ & $D-F, F-D$ & $\begin{array}{l}\text { B4- Centre of the bulge facing point } 4 \text { in Lower Vocal circle. } \\
\text { D9-Centre of the depression facing point 9 in Lower Vocal circle }\end{array}$ \\
\hline $\mathrm{Fa}$ & $F-N, N-F$ & $\begin{array}{l}\text { B3-Centre of the bulge facing point 3 in Lower Vocal circle. } \\
\text { D10-Centre of the depression facing point 10 in Lower Vocal circle }\end{array}$ \\
\hline $\mathrm{Na}$ & $N-T, T-N$ & $\begin{array}{l}\text { B2-Centre of the bulge facing point 2 in Lower Vocal circle. } \\
\text { D11-Centre of the depression facing point 11 in Lower Vocal circle }\end{array}$ \\
\hline $\mathrm{Ta}$ & & $\begin{array}{l}\text { B1-Centre of the bulge facing point 1 in Lower Vocal circle. } \\
\text { D12-Centre of the depression facing point 12 in Lower Vocal circle }\end{array}$ \\
\hline
\end{tabular}

\subsubsection{Re-positioning of unmixed sounds in the Vocal Circle}

Bulges and depressions observed on visible surface of the tongue, for sounds in Upper Vocal Circle, face points in the Lower Vocal Circle. Similarly, for sounds belonging to Lower Vocal Circle, the bulges and depressions, observed on visible surface of the tongue, face points in Upper Vocal Circle. For example, the B \& D corresponding to THa, which belongs to Upper Vocal Circle, face points $12 \& 1$ respectively in Lower Vocal Circle.

A key step of this work is to establish a method to relate bulges and depressions $(B \& D)$ present on the image of a given character to numbered bulges \& depressions $(B \& D)$ of unmixed sounds. This process is presented Table 5 Representation of UNMIXED Sounds using B \& D. In order to make this process easier, 12 unmixed sounds of Upper Vocal Circle are re-positioned in Lower part of Vocal circle and 12 unmixed sounds of Lower Vocal Circle are re-positioned in Upper half of the Vocal Circle.

Figure 2 - Representation of unmixed or basic sounds after re-positioning

\section{VOCAL CIRCLEIV.CL.MODIFED}
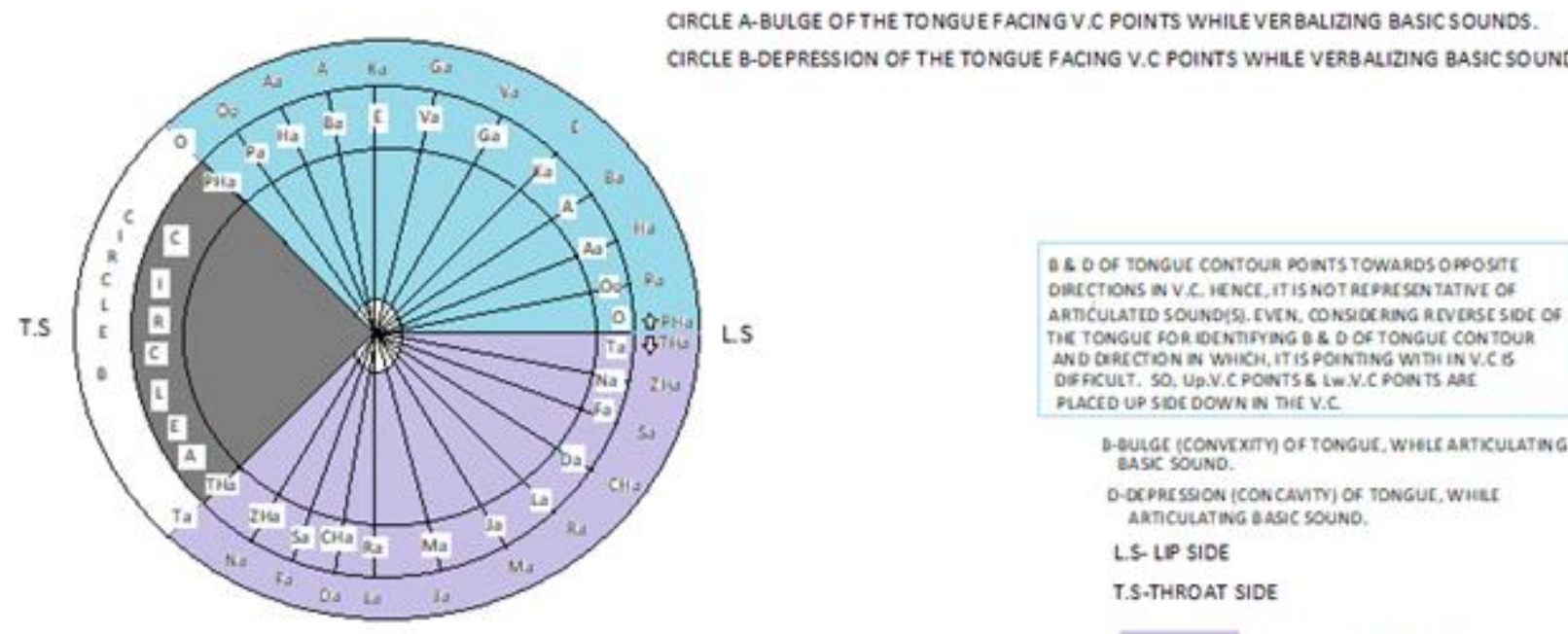

Figure 2 has a two layered circle. The outer layer of double layered vocal circle, referred to as circle A, contains numbered points representing depressions associated with unmixed sounds. But the order of points placed in inner layer of vocal circle, referred to as circle B, is reversed compared to that in circle A. Inner circle B contains numbered points for bulges associated with unmixed sounds. This helps to appropriately relate a B \& D to the corresponding sound. 


\subsection{Relate Images of Characters and the corresponding sounds}

All unmixed sounds along with their related B \& D need to be placed geometrically in exact locations based on degrees of variation. For example, points belonging to positions approximately, $0^{0}, 45^{\circ}, 90^{\circ} \& 135^{\circ}$ in each semi vocal circle have to be identified to derive relative positions of rest of the points.

So, a few characters from previously deciphered ancient scripts or ancient writing systems consisting of (1) Egyptian Hieroglyphs \& (2) Linear B script are selected.

Sound of each character from the script is matched with an unmixed sound. The angular orientation of the B \& D of the character or part of the character under analysis is noted and then used to accordingly position B \& D of matched unmixed sounds in vocal circle.Table 3 and 4 contain details of how this exercise has been done for a few characters. More details are discussed in sections - 3.1 EGYPTIAN HIEROGLYPHS \& 3.2 Linear B Syllabary.

Table 3 - Egyptian Script Characters (HIEROGLYPHS ) related to sounds

\begin{tabular}{|c|c|c|c|c|}
\hline $\begin{array}{l}\text { S. } \\
\text { No. }\end{array}$ & GLYPH & $\begin{array}{lr}\text { GLYPH } & \text { WITH } \\
\text { ARROWS } & \text { FOR } \\
\text { B \& D* } & \end{array}$ & $\begin{array}{l}\text { PREVIOUSLY } \\
\text { ESTABLISHED GLYPH } \\
\text { SOUND }\end{array}$ & $\begin{array}{l}\text { CORRELATION BETWEEN B \& D OF THE } \\
\text { IMAGE OF THE GLYPH WITH THE B \& D } \\
\text { OF THE RELATED SOUND }\end{array}$ \\
\hline 1 & $C$ & T.S $\bigcap_{126}$ & $\begin{array}{l}\mathbf{T a}^{2} \text { for this orientation. } \\
\text { "a" suffixed to all letters in } \\
\text { upper case is pronounced as } \\
\text { in "similar", but is relatively } \\
\text { short and silent. }\end{array}$ & $\begin{array}{l}\text { Ta consists of } 1 \mathrm{~B} \text { and } 12 \mathrm{D} \text {. } \\
\text { This glyph represents bread. } \\
\text { The reason for considering the edge }\left(0^{0}\right) \text { of the } \\
\text { bread for allotting the sound value component } \\
\text { 1B is because features considered for analysis } \\
\text { of glyphs } \\
\text { to be different. Later two glyphs have Ra as } \\
\text { their sound values. } \\
\text { Based on the confirmed position of } 1 \mathrm{~B} \text { of the } \\
\text { given glyph } \bigcirc \text { the other component D is } \\
\text { calculated as follows } 13-1(\mathrm{~B})=12(\mathrm{D}) \text {, and is } \\
\text { located in } 12 \text { th position in the lower half of the } \\
\text { vocal circle (Up.V.C). } \\
\text { It needs to be stressed that } 1 \mathrm{~B} \text { 's of both semi } \\
\text { vocal circles appear at approximately } 0^{0} \\
\text { positions on L.S side in the vocal circle. Based } \\
\text { on their complementary component } \mathrm{D} \text {, they are } \\
\text { discriminated as whether they are } 1 \mathrm{~B} \text { of either } \\
\text { lower or upper vocal circle. } \\
\text { Sound of this glyph- } 126 \text { is } \\
\text { after position of its confirmed as Ta } \\
\text { approximately } 0^{0} \text { (1B) \& } \mathbf{1 3 5} \text { (12D) are located } \\
\text { in the lower half of the V.C (Up.V.C). } \\
\text { Specific features that are considered for the } \\
\text { analysis of this glyph, differentiates it from } \\
\text { other glyphs. }\end{array}$ \\
\hline
\end{tabular}




\begin{tabular}{|c|c|c|c|c|}
\hline $\begin{array}{l}\text { S. } \\
\text { No. }\end{array}$ & GLYPH & $\begin{array}{lr}\text { GLYPH } & \text { WITH } \\
\text { ARROWS } & \text { FOR } \\
\text { B \& D* } & \end{array}$ & $\begin{array}{l}\text { PREVIOUSLY } \\
\text { ESTABLISHED GLYPH } \\
\text { SOUND }\end{array}$ & $\begin{array}{l}\text { CORRELATION BETWEEN B \& D OF THE } \\
\text { IMAGE OF THE GLYPH WITH THE B \& D } \\
\text { OF THE RELATED SOUND }\end{array}$ \\
\hline 2 & $<$ & T.S & $\begin{array}{l}\mathbf{R a}^{3} \text { for this orientation. } \\
\text { "a" suffixed to all letters in } \\
\text { upper case is pronounced as } \\
\text { in "similar", but is relatively } \\
\text { short and silent. }\end{array}$ & $\begin{array}{l}\text { Ra consists of } 8 \mathrm{~B} \text { and } 5 \mathrm{D} \text {. } \\
\text { This glyph represents mouth. } \\
\text { Based on the structure and sound of the glyph, } \\
\text { the position of } \mathrm{B} \text { is located at } 8 \text { facing lower } \\
\text { half of vocal circle i.e., } 8 \mathrm{~B} \text {. The other } \\
\text { component } \mathrm{D} \text { is calculated as follows-13-8(B) } \\
=5(\mathrm{D}) \text {, and is located in } 5 \text { th position in the } \\
\text { lower half of vocal circle. Sound Ra is } \\
\text { confirmed along with position of its } \\
\text { components at approximately } \mathbf{9 0}^{\mathbf{0}}(\mathbf{8 B}) \& \mathbf{4 5}^{\mathbf{0}} \\
\text { (5D) in the Up.V.C- } \\
\text { features that are considered for the analysis of } \\
\text { this Glyph, differentiates it from other Glyphs. }\end{array}$ \\
\hline 3 & & T.S & $\begin{array}{l}\text { La for this orientation. } \\
\text { "a" suffixed to all letters in } \\
\text { upper case is pronounced as } \\
\text { in "similar", but is relatively } \\
\text { short and silent. }\end{array}$ & $\begin{array}{l}\text { La consists of } 5 \mathrm{~B} \text { and } 8 \mathrm{D} \text {. } \\
\text { This glyph represents a resting lion. } \\
\text { Based on the structure and sound, the position } \\
\text { of } \mathrm{D} \text { is located at point } \mathbf{8} \text { and the other } \\
\text { component } \mathrm{B} \text { is calculated as follows- } 13-8(\mathrm{D}) \\
=5(\mathrm{~B}) \text {, and located in } 5 \text { th position facing lower } \\
\text { half of the vocal circle. The sound La is } \\
\text { confirmed after position of its components are } \\
\text { located at approximately } \mathbf{9 0}^{\mathbf{0}}(\mathbf{8 D}) \& \mathbf{4 5}^{\mathbf{0}} \text { (5B) } \\
\text { in the Up.V.C. Specific features that are } \\
\text { considered for the analysis of this glyph, } \\
\text { differentiates it from other glyphs. Features } \\
\text { considered in this case are, head of the } \\
\text { recumbent lion with mane along with its } \\
\text { typically bent tail in the hind part. }\end{array}$ \\
\hline 4 & & T.S & $\begin{array}{l}\mathbf{K a}^{5} \text {.for this orientation. } \\
\text { "a" suffixed to all letters in } \\
\text { upper case is pronounced as } \\
\text { in "similar", but is relatively } \\
\text { short and silent. }\end{array}$ & $\begin{array}{l}\text { Ka consists of } 5 \mathrm{~B} \text { and } 8 \mathrm{D} \text {. } \\
\text { This glyph represents a wickerwork basket with } \\
\text { handle. } \\
\text { Based on the structure and sound, the position } \\
\text { of } \mathbf{8 D} \text { is located and the other component B is } \\
\text { calculated as such, 13-8(D) }=\mathbf{5}(\mathrm{B}) \text {, and located } \\
\text { in } \mathbf{5 t h} \text { position facing upper half of the vocal } \\
\text { circle ( Lw.V.C). The sound Ka is confirmed } \\
\text { after position of its components are located at } \\
\text { approximately } \mathbf{9 0}^{\mathbf{0}} \text { (8D) \& } \mathbf{4 5}^{\mathbf{0}} \text { (5B) in the } \\
\mathbf{L w . V . C} \text {. Specific features that are considered } \\
\text { for the analysis of this glyph, differentiates it } \\
\text { from other glyphs. Features considered in this }\end{array}$ \\
\hline
\end{tabular}




\begin{tabular}{|c|c|c|c|c|}
\hline S. & GLYPH & $\begin{array}{lr}\text { GLYPH } & \text { WITH } \\
\text { ARROWS } & \text { FOR } \\
\text { B \& D* } & \end{array}$ & $\begin{array}{l}\text { PREVIOUSLY } \\
\text { ESTABLISHED GLYPH } \\
\text { SOUND }\end{array}$ & $\begin{array}{l}\text { CORRELATION BETWEEN B \& D OF THE } \\
\text { IMAGE OF THE GLYPH WITH THE B \& D } \\
\text { OF THE RELATED SOUND }\end{array}$ \\
\hline & & & & $\begin{array}{l}\text { case are, curvatures of basket and that of its } \\
\text { handle. }\end{array}$ \\
\hline 5 & 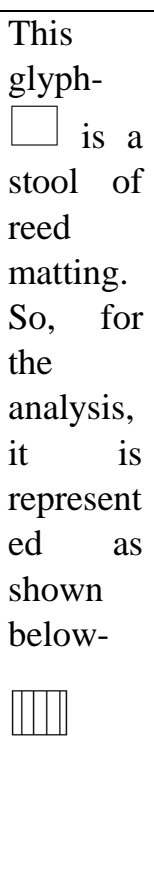 & $\stackrel{118}{12}^{10}$ & $\begin{array}{l}\mathbf{P H a} \mathbf{a}^{6} \text { for this orientation. } \\
\text { "a" suffixed to all letters in } \\
\text { upper case is pronounced as } \\
\text { in "similar", but is relatively } \\
\text { short and silent }\end{array}$ & $\begin{array}{l}\text { PHa consists of 1D and 12B. Pa pronounced } \\
\text { with slight stress on Ha, creates a sound- PHa. } \\
\text { But, Fa is a different sound. } \\
\text { This glyph represents a stool of reed matting. } \\
\text { Based on the structure and sound, the position } \\
\text { of D (depression) observed between vertically } \\
\text { placed individual reeds is located at point } 1 . \\
\text { The complementary component B is calculated } \\
\text { as follows- 13-1(D) =12(B). Position of point } \\
12 \text { (B) faces upper half of the vocal circle. The } \\
\text { sound PHa is confirmed after position of its } \\
\text { components are located at approximately } \mathbf{1 3 5}^{\mathbf{0}} \\
\text { (12B) \& } \mathbf{0}^{\mathbf{0}} \text { (1D) in the upper half of the vocal } \\
\text { circle (Lw.V.C). Specific features that are } \\
\text { considered for the analysis of this glyph, } \\
\text { differentiates it from other glyphs. Features } \\
\text { considered in this case are, sharp corners of the } \\
\text { stool and depressions between reeds. }\end{array}$ \\
\hline
\end{tabular}

* Left side of each image is throat side \& right side is towards lip side

All images are created using Microsoft Paint without missing anything relevant. Table of standard glyph codes are provided for glyphs to be compared with that presented in original site ${ }^{1}$.

Unicodes Of Egyptian Hieroglyphs Discussed In Table ${ }^{1}$ :

\begin{tabular}{|l|l|l|l|}
\hline S.No. (as in Table 3) & UNICODES & S.No. (as in Table 3) & UNICODES \\
\hline 1 & U+133CF & 0 & U+131F3 \\
\hline 2 & U+1308B & & U+ 133A1 \\
\hline 3 & U+130ED & $\square$ & U+ 132AA \\
\hline
\end{tabular}

Table 4- Linear B Script (SYLLABARY) Characters related to sounds

\begin{tabular}{|c|c|c|c|c|}
\hline $\begin{array}{l}\text { S. } \\
\text { No. }\end{array}$ & $\begin{array}{l}\text { CHARA } \\
\text {-CTER }\end{array}$ & $\begin{array}{l}\text { CHARACTER } \\
\text { WITH ARROWS } \\
\text { FOR B \& D }\end{array}$ & $\begin{array}{l}\text { PREVIOUSLY } \\
\text { ESTABLISHED SCRIPT } \\
\text { SOUND }\end{array}$ & $\begin{array}{l}\text { CORRELATION BETWEEN B \& D OF THE } \\
\text { IMAGE OF THE CHARACTER WITH B \& D } \\
\text { OF THE RELATED SOUND }\end{array}$ \\
\hline 1 & + & 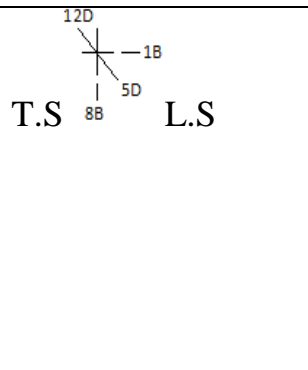 & $\begin{array}{l}\mathrm{Ra}-\mathrm{O}=\mathrm{RO}^{7} \text { for this } \\
\text { orientation. } \\
\text { "a" suffixed to all letters } \\
\text { in upper case is } \\
\text { pronounced as in } \\
\text { "similar", but is relatively }\end{array}$ & $\begin{array}{l}\text { RO is the sound. End point of a line is considered } \\
\left.\text { as bulge (B). Ra consists of } 8 \mathrm{~B} \text { (approx. } 90^{\circ}\right) \& \\
5 \mathrm{D}\left(45^{0}\right) \text { in lower half of the V.C (Up.V.C). O } \\
\left.\text { consists of } 1 \mathrm{~B}\left(0^{0}\right) \& 12 \mathrm{D} \text { (approx. } 135^{\circ}\right) \text { in the } \\
\text { upper half of the V.C (Lw.V.C). } \\
\text { Sounds Ra \& O are put together in anti- } \\
\text { clockwise manner beginning from lower left }\end{array}$ \\
\hline
\end{tabular}




\begin{tabular}{|c|c|c|c|c|}
\hline $\begin{array}{l}\text { S. } \\
\text { No. }\end{array}$ & $\begin{array}{l}\text { CHARA } \\
\text {-CTER }\end{array}$ & $\begin{array}{l}\text { CHARACTER } \\
\text { WITH ARROWS } \\
\text { FOR B \& D }\end{array}$ & $\begin{array}{l}\text { PREVIOUSLY } \\
\text { ESTABLISHED SCRIPT } \\
\text { SOUND }\end{array}$ & $\begin{array}{l}\text { CORRELATION BETWEEN B \& D OF THE } \\
\text { IMAGE OF THE CHARACTER WITH B \& D } \\
\text { OF THE RELATED SOUND }\end{array}$ \\
\hline & & & short and silent. & side. \\
\hline 2 & 7 & $\mathrm{~T} . \mathrm{S}^{12 \mathrm{D}}{ }^{1 \mathrm{D}} \mathrm{L}$ & $\begin{array}{l}\mathrm{Ta}-\mathrm{O}=\mathrm{TO}^{7} \text { for this } \\
\text { orientation. } \\
\text { "a" suffixed to all letters } \\
\text { in upper case is } \\
\text { pronounced as in } \\
\text { "similar", but is relatively } \\
\text { short and silent. }\end{array}$ & $\begin{array}{l}\text { TO is the sound. The numbering of B \& D is } \\
\text { done in clockwise manner beginning from top } \\
\text { left side (T.S) to right side (L.S) of the structure } \\
\text { towards its lower part. End point of a line is } \\
\text { considered as bulge (B). Features (circled) that } \\
\text { differentiate the given character- } \\
\text { closely resembling character- }+ \text { are used for } \\
\text { derivation of sounds Ta \& O. Ta consists of 12D } \\
\text { (approx. } \mathbf{1 3 5}^{\mathbf{0}} \text { ) \& } \mathbf{1 D} \text { (approx. } \mathbf{0}^{\mathbf{0}} \text { ) facing the } \\
\text { lower half of the V.C (Up.V.C). O consists of } \\
\text { 12D (approx. } \mathbf{1 3 5}^{\mathbf{0}} \text { ) \& } \mathbf{1 B} \text { (approx. } \mathbf{0}^{\mathbf{0}} \text { ) facing the } \\
\text { upper half of the V.C (Lw.V.C). } \\
\text { But, sounds Ta \& O (=TO) are added in } \\
\text { anticlockwise manner, beginning from lower left } \\
\text { side to right side and thereon towards upper right } \\
\text { side band then to upper left side. }\end{array}$ \\
\hline
\end{tabular}

* Left side of each image is throat side \& right side is towards lip side All images are created using Microsoft Paint without missing anything relevant. Table of standard script codes are provided for characters to be compared with that presented in original site $^{7}$.

\section{Unicodes Of Characters From Linear B Syllabary Listed Above?:}

\begin{tabular}{|l|l|}
\hline S.No. & UNICODES \\
\hline 1 & $\mathrm{U}+1002 \mathrm{~B}$ \\
\hline 2 & $\mathrm{U}+10035$ \\
\hline
\end{tabular}

In the column 5 in Table 3 and

Table 4, positions of points $1,5,8 \& 12$ representing sounds at $0^{0}, 45^{\circ}, 90^{\circ} \& 135^{\circ}$ in both semi vocal circles are shown. This data is used to modify the Figure 2 to show exact angles in both semi-vocal circles. The modified

Figure 3 is shown below. 
Figure 3 - Representation of unmixed or basic sounds at positions 00, 450, $900 \& 1350$ in each semi-vocal circle VOCAL CIRCLE (V.C)-MODIFIED

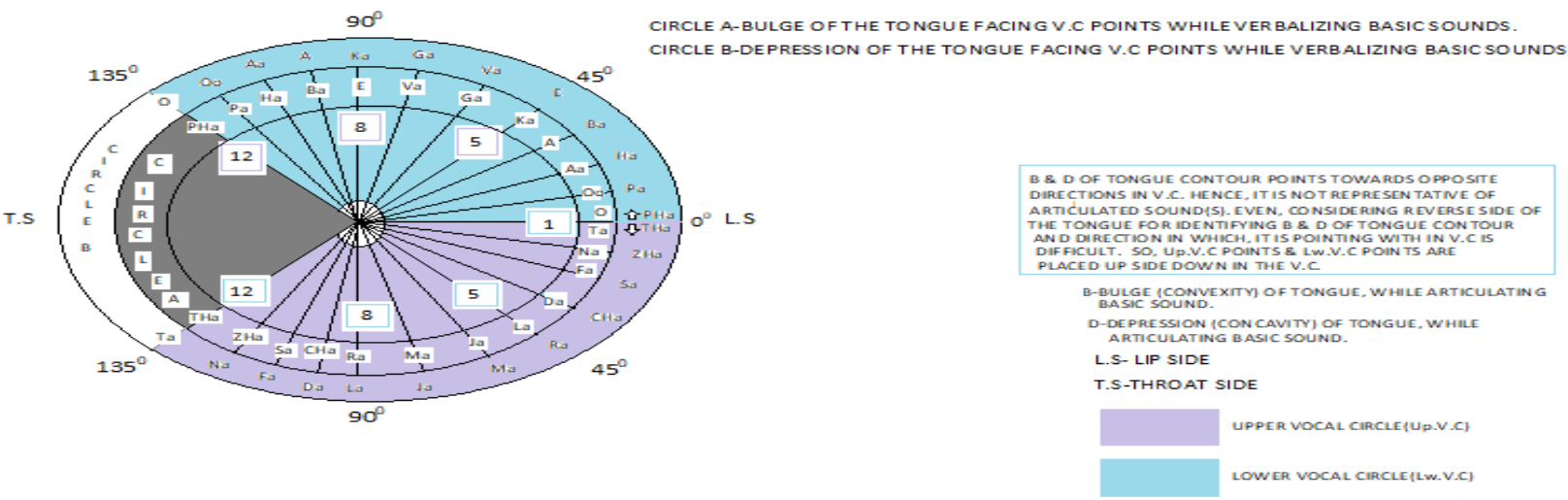

Using Table 3 and Table 4, B \& Ds of 8 unmixed sounds are positioned at $0^{\circ}(1), 45^{\circ}(5), 90^{\circ}(8) \& 135^{\circ}(12)$. These positions can be considered as standard positions. Further, positions of B \& Ds of remaining unmixed sounds are identified relative to the standard positions of B \& Ds of 8 sounds. The final positions are reflected in Figure 3.

The Table 5 contains positions of all unmixed sounds and is used to number B \& Ds observed on the image of a character unaided by vocal circle.

Table 5 - Representation of UNMIXED Sounds using B \& D

\begin{tabular}{|c|c|c|c|c|}
\hline $\begin{array}{l}\text { S. } \\
\text { No. }\end{array}$ & $\begin{array}{l}\text { Up.V.C } \\
\text { SOUND } \\
\text { PLACED IN } \\
\text { LOWER SEMI } \\
\text { CIRCLE } \\
\\
\text { B/D }\end{array}$ & $\begin{array}{l}\text { DIAG. REPRESENTATION } \\
\text { OF B \& D OF SOUND TO BE } \\
\text { MATCHED WITH B \& D } \\
\text { PRESENT ON IMAGES OF A } \\
\text { GIVEN CHARACTER. } \\
\text { (Left side of each image is } \\
\text { throat side \& right side is } \\
\text { towards lip side) }\end{array}$ & $\begin{array}{l}\text { LW.V.C } \\
\text { SOUND } \\
\text { PLACED IN } \\
\text { UPPER SEMI } \\
\text { CIRCLE } \\
\text { B /D }\end{array}$ & $\begin{array}{l}\text { DIAG. REPRESENTATION } \\
\text { OF B \& D OF SOUND TO BE } \\
\text { MATCHED WITH B \& D } \\
\text { PRESENT ON IMAGES OF A } \\
\text { GIVEN CHARACTER. } \\
\text { (Left side of each image is } \\
\text { throat side \& right side is } \\
\text { towards lip side) }\end{array}$ \\
\hline 1 & $\begin{array}{ll}\text { THa } & 12 / 1\end{array}$ & $\left(1,125^{1}\right.$, & $\begin{array}{ll}\mathrm{PHa} & 12 / 1\end{array}$ & \\
\hline 2 & $\begin{array}{ll}\mathrm{ZHa} & 11 / 2\end{array}$ & & $\mathrm{~Pa} \quad 11 / 2$ & \\
\hline 3 & $10 / 3$ & $=-1 \infty$ & $\mathrm{Ha} \quad 10 / 3$ & \\
\hline 4 & $\mathrm{CHa}$ & & $\mathrm{Ba}$ & \\
\hline 5 & $\mathrm{Ra}$ & $\varphi_{8} \varphi_{5}^{-1}, \varphi_{5}$ & $8 / 5$ & \\
\hline 6 & $\mathrm{Ma}$ & $\Leftrightarrow /\left.\left.\right|_{6}\right|_{6} ^{\infty}, \frac{6}{6}$ & $\mathrm{Va}$ & \\
\hline 7 & $6 / 7$ & 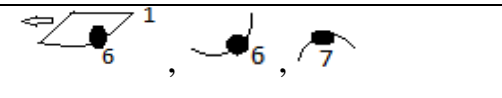 & $\mathrm{Ga}$ & \\
\hline 8 & $\mathrm{La}$ & $\overrightarrow{8}, \Rightarrow 8 \Leftrightarrow, \boldsymbol{\sigma}_{5}^{1}, \bullet_{5}$ & $\mathrm{Ka}$ & $\vartheta_{1}^{5}, \rho^{5}$ \\
\hline
\end{tabular}




\begin{tabular}{|c|c|c|c|c|}
\hline No. & $\begin{array}{l}\text { Up.V.C } \\
\text { SOUND } \\
\text { PLACED IN } \\
\text { LOWER SEMI } \\
\text { CIRCLE } \\
\\
\text { B/D }\end{array}$ & $\begin{array}{l}\text { DIAG. REPRESENTATION } \\
\text { OF B \& D OF SOUND TO BE } \\
\text { MATCHED WITH B \& D } \\
\text { PRESENT ON IMAGES OF A } \\
\text { GIVEN CHARACTER. } \\
\text { (Left side of each image is } \\
\text { throat side \& right side is } \\
\text { towards lip side) }\end{array}$ & $\begin{array}{l}\text { LW.V.C } \\
\text { SOUND } \\
\text { PLACED IN } \\
\text { UPPER SEMI } \\
\text { CIRCLE } \\
\text { B /D }\end{array}$ & $\begin{array}{l}\text { DIAG. REPRESENTATION } \\
\text { OF B \& D OF SOUND TO BE } \\
\text { MATCHED WITH B \& D } \\
\text { PRESENT ON IMAGES OF A } \\
\text { GIVEN CHARACTER. } \\
\text { (Left side of each image is } \\
\text { throat side \& right side is } \\
\text { towards lip side) }\end{array}$ \\
\hline 9 & $4 / 9$ & $\left.\Rightarrow \bullet_{4}^{1}, 9\right), \boldsymbol{\phi}_{4}$ & $4 / 9$ & \\
\hline 10 & $3 / 10$ & $\left.\left.{ }_{10}, \infty, 10\right),\right\rangle_{3}$ & $3 / 10$ & $\Rightarrow \leqslant, 10), 9^{3}$ \\
\hline 11 & $2 / 11$ & $\Rightarrow /\left.11\right|_{8}$ & $2 / 11$ & $\Rightarrow 11 \mid$ \\
\hline 12 & $1 / 12$ & $\left.\left.\overrightarrow{129^{1}}, \overrightarrow{12}\right),\right\rangle_{1}$ & $1 / 12$ & $\stackrel{12}{8}, 12$ \\
\hline
\end{tabular}

\section{Explanation:}

- Centres of bulges and depressions of unmixed sounds can face 24 points and all of them are presented in Table 5 $\&$ fig 2 .

- $B / D$ - Bulge and Depression on the visible side of the tongue while articulating the unmixed sound. T.S - Throat side of vocal circle. L.S - Lip side of vocal circle. Up.V.C- Upper Vocal Circle. Lw.V.C- Lower Vocal Circle.

- A Curve / angle and a dot - represents bulge and depression on the tongue (tongue contour) and its centre point respectively, while verbalizing an unmixed sound.

- Number next to a dot - it is the number of the point facing the dot located on centre point of bulge and depression within a semi vocal circle.

- Arrow- represents direction of shift of an arm of an angle from a standard position. Standard positions of following points are- $1\left(\right.$ at $\left.0^{0}\right), 5\left(\right.$ at $\left.45^{\circ}\right), 8\left(\right.$ at $\left.90^{\circ}\right) \& 12$ (at $135^{\circ}$ ). Degrees of variations are calculated from lip side.There could be images whose $\mathrm{B}$ and $\mathrm{D}$ are not complementary i.e. $\mathrm{B}+\mathrm{D} \neq 13$. In such cases, refer to

- Table 6.

Table 6 - Examples of exceptional Cases where $B+D \neq 13$

\begin{tabular}{|l|l|l|}
\hline $\begin{array}{l}\text { S. } \\
\text { No. }\end{array}$ & $\begin{array}{l}\text { PRESENTATION } \\
\text { OF ANALYSIS } \\
\text { OF IMAGE OF A } \\
\text { CHARACTER }\end{array}$ & UNMIXED SOUND \\
\hline 1 & & $\begin{array}{l}\text { On the left is analysis of an image of a character, with an anomalous B \& D } \\
\text { formation. Vertex(centre) represents depression. In this case, depression points } \\
\text { towards 4, while B is at } 8 . \\
\text { The vertex (centre) of angle formed by segments A \& C1 faces point 5. } \\
\text { When the segment C1 moves down, the vertex of angle formed by segments A \& } \\
\text { C2 faces point 4(marked by thinner line) instead of 5. } \\
\text { The difference of point one (1) in the position of D, at } 4 \text { instead of being at 5, is } \\
\text { waived off to make B }+\mathrm{D}=13 . \\
\text { In this situation, the resultant sound will be EB. E is the dominant sound represented }\end{array}$ \\
\hline
\end{tabular}




\begin{tabular}{|c|c|c|}
\hline $\begin{array}{l}\text { S. } \\
\text { No. }\end{array}$ & $\begin{array}{l}\text { PRESENTATION } \\
\text { OF ANALYSIS } \\
\text { OF IMAGE OF A } \\
\text { CHARACTER }\end{array}$ & UNMIXED SOUND \\
\hline & & $\begin{array}{l}\text { by } \mathrm{B} \text {, which is at a standard position } 8\left(90^{\circ}\right) \text { compared to the sound } B \text {, added as } \\
\text { suffix, represented by } \mathrm{D} \text { at a relative position } 4\left(<45^{\circ}\right) \text {. This is done to include the } \\
\text { significance of deviation of any component. }\end{array}$ \\
\hline 2 & $\begin{array}{r}90^{\circ} \\
\text { (8) }\end{array}$ & $\begin{array}{l}\text { On the left is analysis of an image of a character, with an anomalous } \mathrm{B} \& \mathrm{D} \\
\text { formation. Vertex represents depression. In this case, depression points towards } 4 \text {, } \\
\text { while } \mathrm{B} \text { is at } 8 \text {. } \\
\text { The vertex (centre) of angle formed by segments } \mathrm{A} \& \mathrm{C} 1 \text { faces point } 5 \text {. } \\
\text { When the segment } \mathrm{C} 1 \text { moves up, the vertex of angle formed by segments } \mathrm{A} \& \mathrm{C} 2 \\
\text { faces point } 4 \text { (marked by thinner line) instead of } 5 \text {. } \\
\text { The difference of point one (1) in the position of } \mathrm{D} \text {, at } 4 \text { instead of being at } 5 \text {, is } \\
\text { waived off to make } \mathrm{B}+\mathrm{D}=13 \text {. } \\
\text { In this situation, the resultant sound will be } \mathrm{RCH} \text {. Ra is the dominant sound } \\
\text { represented by B, which is at a standard position } 8\left(90^{\circ}\right) \text { compared to the sound } C H a \text {, } \\
\text { added as suffix, represented by } \mathrm{D} \text { at a relative position } 4\left(<45^{\circ}\right) \text {. This is done to } \\
\text { include the significance of deviation of any component. }\end{array}$ \\
\hline 3 & & $\begin{array}{l}\text { On the left is analysis of an image of a character, with an anomalous } \mathrm{B} \& \mathrm{D} \\
\text { formation. Vertex represents depression. In this case, depression points towards } 11 \text {, } \\
\text { while } \mathrm{B} \text { is at } 1 \text {. } \\
\text { The vertex (centre) of right angle formed by segments } \mathrm{A} 1 \text { \& } \mathrm{C} \text { faces point } 12 \\
\left(135^{\circ}\right) \text {. } \\
\text { When the segment A1 moves up, the vertex of angle formed by segments A2 \& C } \\
\text { faces point } 11 \text { (marked by darker line) instead of } 12 \text {. } \\
\text { The difference of point one (1) in the position of } \mathrm{D} \text {, at } 11 \text { instead of being at } 12 \text {, is } \\
\text { waived off to make } \mathrm{B}+\mathrm{D}=13 \text {. } \\
\text { In this situation, the resultant sound will be OOo }(\mathrm{O}-O o) \text {. O is the dominant sound } \\
\text { represented by B, which is at a standard position } 1\left(0^{0}\right) \text { compared to the sound } O o \text {, } \\
\text { added as suffix, represented by D at a relative position } 11\left(<135^{\circ}\right) \text {. This is done to } \\
\text { include the significance of deviation of any component. }\end{array}$ \\
\hline 4 & & $\begin{array}{l}\text { On the left is analysis of an image of a character, with an anomalous B \& D } \\
\text { formation. Vertex represents depression. In this case, depression points towards } 11 \text {, } \\
\text { while B is at } 1 \text {. } \\
\text { The vertex (centre) of right angle formed by segments A1 \& C faces point } 12 \\
\left(135^{0}\right) \text {. } \\
\text { When the segment A1 moves down, the vertex of angle formed by segments A2 \& } \\
\text { C faces point } 11 \text { (marked by darker line) instead of } 12 \text {. } \\
\text { The difference of point one (1) in the position of } \mathrm{D} \text {, at } 11 \text { instead of being at } 12 \text {, is } \\
\text { waived off to make } \mathrm{B}+\mathrm{D}=13 \text {. } \\
\text { In this situation, the resultant sound will be } \mathrm{T} N \text {. } \mathrm{T} \text { is the dominant sound represented }\end{array}$ \\
\hline
\end{tabular}




\begin{tabular}{|c|c|c|}
\hline $\begin{array}{l}\text { S. } \\
\text { No. }\end{array}$ & $\begin{array}{l}\text { PRESENTATION } \\
\text { OF ANALYSIS } \\
\text { OF IMAGE OF A } \\
\text { CHARACTER }\end{array}$ & UNMIXED SOUND \\
\hline & & $\begin{array}{l}\text { by } \mathrm{B} \text {, which is at a standard position } 1\left(0^{\circ}\right) \text { compared to the sound } N \text {, added as suffix, } \\
\text { represented by } \mathrm{D} \text { at a relative position } 11\left(<135^{\circ}\right) \text {. This is done to include the } \\
\text { significance of deviation of any component. }\end{array}$ \\
\hline 5 & 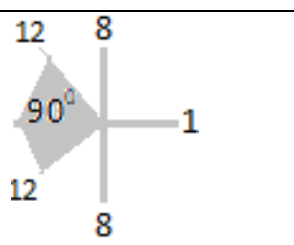 & $\begin{array}{l}\text { DARK ZONE } \\
\text { DARK ZONE- Area lacking tongue movements and its contours that are relevant } \\
\text { for this study. Its upper and lower extents are marked by points representing } 12 \\
\text { belonging to both, upper \& lower vocal circles. Therefore, it is left out of this study. }\end{array}$ \\
\hline
\end{tabular}

\section{Explanation:}

- The above table deals with some specific situations where B \& D of the image of a character do not add up to 13. These are anomalous situations.

- The first situation is where B is in a standard position and only available complementary D component is at a relative position varying by a single point (see $1^{\text {st }}$ item in the table). This variation is waived off to ensure $\mathrm{B}+\mathrm{D}$ $=13$. Now, the resultant sound will be formed by the dominant sound represented by $\mathrm{B}$ and another sound represented by $\mathrm{D}$ which is added as suffix. The $\mathrm{B}$ is at a standard position compared to $\mathrm{D}$ which is at a relative position. This step is taken to include the significance of deviation of any component.

- The second situation is where $\mathrm{D}$ is in a standard position and only available complementary $\mathrm{B}$ component is at a relative position varying by a single point. This variation is waived off to ensure $B+D=13$. Now, the resultant sound will be formed by the dominant sound represented by D and another sound represented by B which is added as suffix. The D is at a standard position compared to B which is at a relative position. This step is taken to include the significance of deviation of any component.

- It should be noted that the variation more than one (1) is not considered.

- This approach is used to include all parts of a character structure for analysis and derive appropriate sound(s) without missing the significance of deviation of any of component.

- B \& D of a derived sound belongs to same semi vocal circle.

2.3 Identify sounds of a few characters of Indus Valley and Oracle Bone scripts

Using the results obtained from previous steps, sounds of a few characters of Indus Valley script and Oracle Bone script are identified and detailed in Table 7 and Table 8 respectively. It should be borne in mind that in most cases B + $\mathrm{D}$ should be 13. In cases, where this condition is not met, an exceptional approach needs to be adopted as detailed in

Table 6. The sequence of steps involved in identification of sounds has been discussed in section

\subsection{Flow Chart for Identifying Sounds of Characters of Ancient Scripts.}

\subsubsection{Numbering of $B$ \& $D$ of Characters}

Allotments of numbers to B \& D begin from left upper quadrant and then follow in a clockwise manner and end in left lower quadrant. In some cases, where a complementary component of a B or D located in left upper quadrant could not be identified in other quadrants of the image, the allotment begins from the adjacent quadrant along the clockwise direction.

Following are guidelines used for numbering B \& D of characters of Indus Valley and Oracle Bone scripts.

a) $0^{\circ}$ is at point 1 (one) on the lip side of vocal circle (V.C) for both semi vocal circles.

b) Points located in regions of $>90^{\circ} \&<90^{\circ}$ of vocal circle (V.C), range between $12-8 \&$ 5-8 respectively.

c) Points located in regions of $90^{0}-45^{\circ} \& 45^{\circ}-0^{\circ}$ on lip side range between $8-5 \& 1-5$ respectively.

d) Points located in regions of $>135^{\circ} \& 135^{\circ}-90^{\circ}$ on throat side are nil \& 8-12 respectively. 
e) Addition of derived unmixed sounds begins from left lower quadrant and follows in anti-clockwise manner and ends in left upper quadrant.

f) Opposite side of a bulge (B) of a character structure is not considered as depression (D), and conversely.

g) There are cases, where only one (of the two) component of a sound is located on the image of a character. On other part of image, both components of the same sound is located. In such cases, the lone component is not shared by one of the two components of same sound located on another part of the image of a character.

h) These sounds, when put together form the complete sound of a character structure. But, a part or more of the sound may be the sound used for that character.

i) Use of a part(s) of the complete sound of a character structure indicates that it is derived from those part(s) of a character structure, which differentiates it from other closely resembling character structures.

\subsubsection{Sounds identified for some characters of Indus Valley Script \& Oracle Bone Script}

The sequence of steps involved in identification of sounds has been discussed in section

3.3 Flow Chart for Identifying Sounds of Characters of Ancient Scripts. In the Table 7, third column has the analysis of the images of selected characters. Using this analysis, go to Table 5 - Representation of UNMIXED Sounds using B $\& \mathrm{D}$ and look for matching entry in columns 3 and 5 (Table 5). If a matching entry is found, then corresponding sound is found from column 2 and 4 (Table 5).

Table 7 - Sounds derived for characters in Indus Valley Script

\begin{tabular}{|c|c|c|c|c|}
\hline $\begin{array}{l}\text { S. } \\
\text { No. }\end{array}$ & $\begin{array}{l}\text { CHAR- } \\
\text { ACTER }\end{array}$ & $\begin{array}{l}\text { CHARACTER } \quad \text { WITH } \\
\text { ARROWS FOR B \& D*. }\end{array}$ & $\begin{array}{l}\text { DERIVED } \\
\text { CHARACTER SOUND }\end{array}$ & $\begin{array}{llll}\text { PROCESS } & \text { OF } & \text { DERIVATION } & \text { OF } \\
\text { SOUND } & & & \end{array}$ \\
\hline 1 & & T.S $\bigwedge_{\text {8D } 5 \text { L L.S }}$ & $\begin{array}{l}\text { Sound is La for this } \\
\text { orientation. } \\
\text { "a" suffixed to all letters } \\
\text { in upper case is } \\
\text { pronounced as in } \\
\text { "similar", but is } \\
\text { relatively short and } \\
\text { silent. }\end{array}$ & $\begin{array}{l}\text { From Table } 5 \text { it can be seen that the sound } \\
\text { associated with this character is La. It } \\
\text { needs to be noted that end point of an arm } \\
\text { is considered as convex or bulge (5B). }\end{array}$ \\
\hline 2 & & 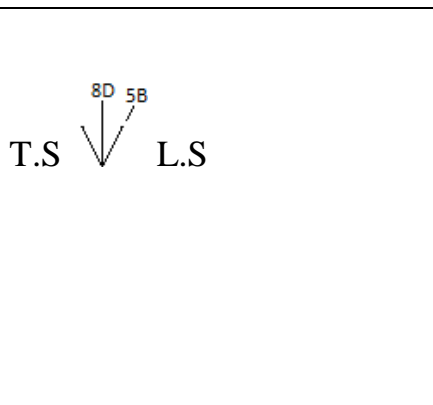 & $\begin{array}{l}\text { Sound is Ka for this } \\
\text { orientation. } \\
\text { "a" suffixed to all letters } \\
\text { in upper case and } \\
\text { pronounced as in } \\
\text { "similar", but are } \\
\text { relatively short and } \\
\text { silent. }\end{array}$ & $\begin{array}{l}\text { From Table } 5 \text { it can be seen that the sound } \\
\text { associated with this character is Ka. } \\
\text { It needs to be noted that end point of an } \\
\text { arm is considered as convex or bulge (5B). }\end{array}$ \\
\hline 3 & 入 & $\begin{array}{l}\text { T.S }{ }_{80}^{\left.\right|^{8 B} \mathrm{LB}} \mathrm{L} . \mathrm{S} \\
\text { Only available D for } 8 \mathrm{~B} \text { in } \\
\text { upper part is in fact 4D. It } \\
\text { is clarified in }\end{array}$ & $\begin{array}{l}\text { Sound is LaEBa for this } \\
\text { orientation. } \\
\text { "a" suffixed to all letters } \\
\text { in upper case is } \\
\text { pronounced as in } \\
\text { "similar", but is } \\
\text { relatively short and } \\
\text { silent. }\end{array}$ & $\begin{array}{l}\text { From Table } 5 \text { it can be seen that the sound } \\
\text { associated with this character is La. } \\
\text { In this analysis, D has a variation and has } \\
\text { been adjusted from } 4 \text { to } 5 \text {. } \\
\text { Use } \\
\text { Table } 6 \text {, do analysis of the variation. The } \\
\text { resultant sound is EBa_(Upper 8B \& 4D). }\end{array}$ \\
\hline
\end{tabular}




\begin{tabular}{|c|c|c|c|c|}
\hline $\begin{array}{l}\text { S. } \\
\text { No. }\end{array}$ & $\begin{array}{l}\text { CHAR- } \\
\text { ACTER }\end{array}$ & $\begin{array}{l}\text { CHARACTER } \quad \text { WITH } \\
\text { ARROWS FOR B \& D*. }\end{array}$ & $\begin{array}{l}\text { DERIVED } \\
\text { CHARACTER SOUND }\end{array}$ & $\begin{array}{l}\text { PROCESS OF DERIVATION } \\
\text { SOUND }\end{array}$ \\
\hline & & $\begin{array}{l}\text { Table } 6 . \\
\text { As segment C moves lower } \\
\text { down to a new position, the } \\
\text { vertex (centre of } \\
\text { depression) of the angle } \\
\text { formed by segments A \& C } \\
\text { faces point } 4 \text { (marked by a } \\
\text { lighter line) instead of 5. }\end{array}$ & & $\begin{array}{l}\text { Sound } \mathbf{E B a} \text { is derived from the upper } \\
\text { vertical line of the given character } \\
\text { feature of the given character differentiates } \\
\text { it from another character- } \wedge \text {. } \\
\mathbf{L E B} \text { is the sound of the complete structure } \\
\text { of the character. }\end{array}$ \\
\hline 4 & 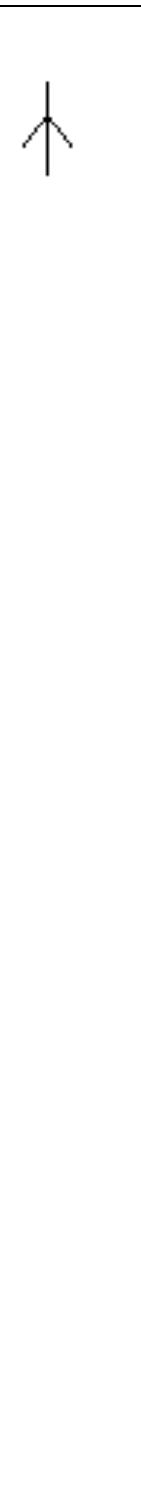 & 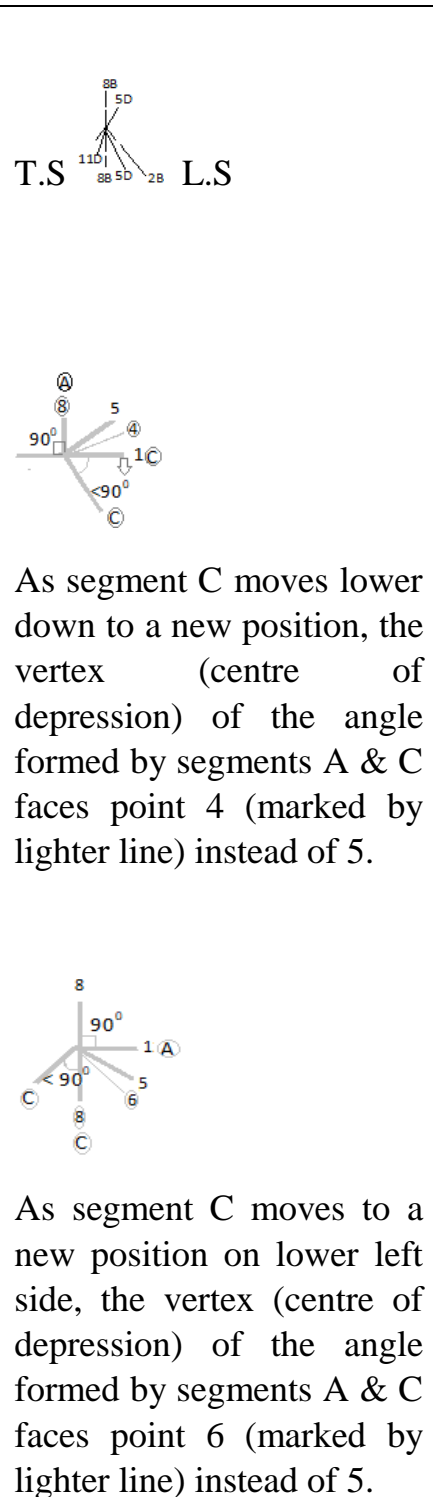 & $\begin{array}{l}\text { Sound is NaRaMaEBa } \\
\text { for this orientation. "a" } \\
\text { suffixed to all letters in } \\
\text { upper case is pronounced } \\
\text { as in "similar", but is } \\
\text { relatively short and } \\
\text { silent. }\end{array}$ & 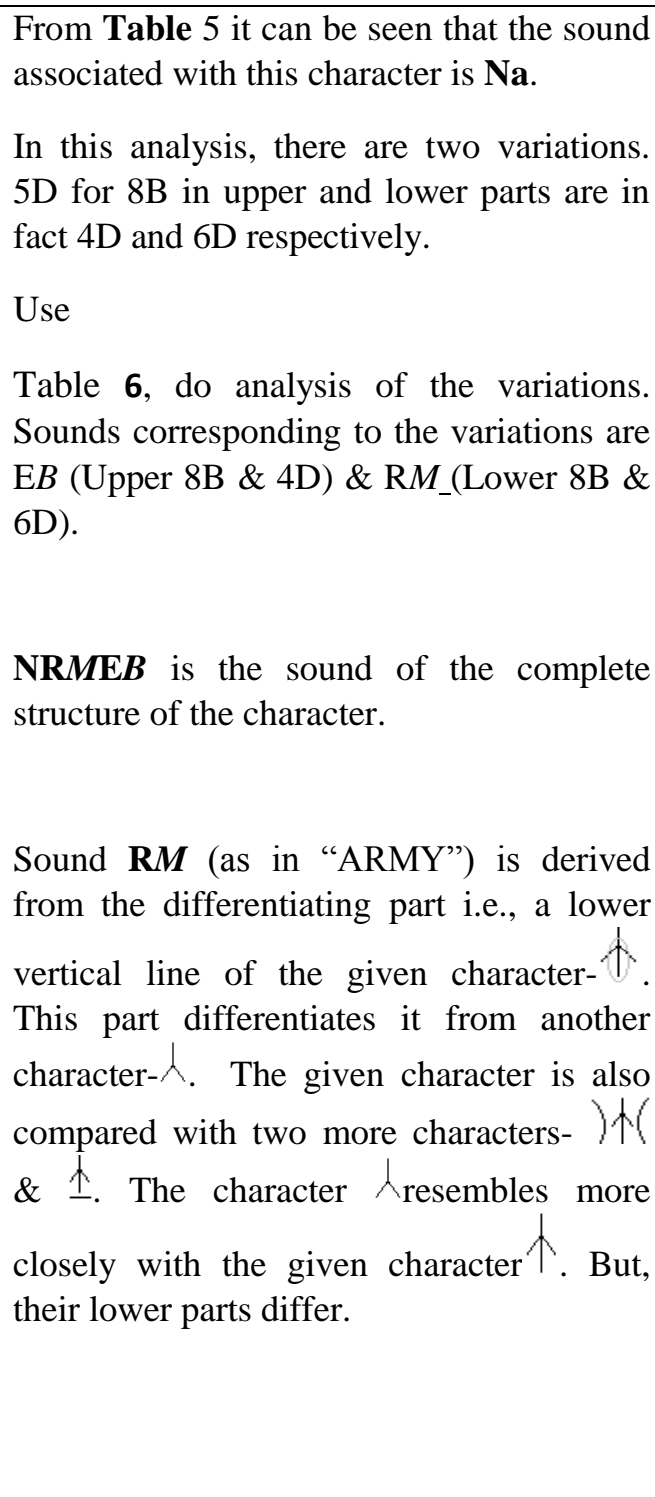 \\
\hline
\end{tabular}




\begin{tabular}{|c|c|c|c|c|}
\hline $\begin{array}{l}\text { S. } \\
\text { No. }\end{array}$ & $\begin{array}{l}\text { CHAR- } \\
\text { ACTER }\end{array}$ & $\begin{array}{l}\text { CHARACTER } \quad \text { WITH } \\
\text { ARROWS FOR B \& D*. }\end{array}$ & $\begin{array}{l}\text { DERIVED } \\
\text { CHARACTER SOUND }\end{array}$ & $\begin{array}{llll}\text { PROCESS } & \text { OF } & \text { DERIVATION } & \text { OF } \\
\text { SOUND } & & & \end{array}$ \\
\hline & & $\begin{array}{l}5 \mathrm{D} \text { for } 8 \mathrm{~B} \text { in upper and } \\
\text { lower parts are in fact } 4 \mathrm{D} \\
\text { and } 6 \mathrm{D} \text { respectively. It is } \\
\text { clarified in } \\
\text { Table } 6 .\end{array}$ & & \\
\hline 5 & & $\begin{array}{l}\text { The only available D for } \\
8 \mathrm{~B} \text { in upper part is in fact } \\
\text { 4D. It is clarified in } \\
\text { Table } 6 . \\
\text { As segment } \mathrm{C} \text { moves lower } \\
\text { down to a new position, the } \\
\text { vertex (centre of } \\
\text { depression) of the angle } \\
\text { formed by segments A \& } \mathrm{C} \\
\text { faces point } 4 \text { (marked by a } \\
\text { lighter line) instead of } 5 \text {. }\end{array}$ & $\begin{array}{l}\text { Sound is LaNaEBa for } \\
\text { this orientation. "a" } \\
\text { suffixed to all letters in } \\
\text { upper case is pronounced } \\
\text { as in "similar", but is } \\
\text { relatively short and } \\
\text { silent. }\end{array}$ & 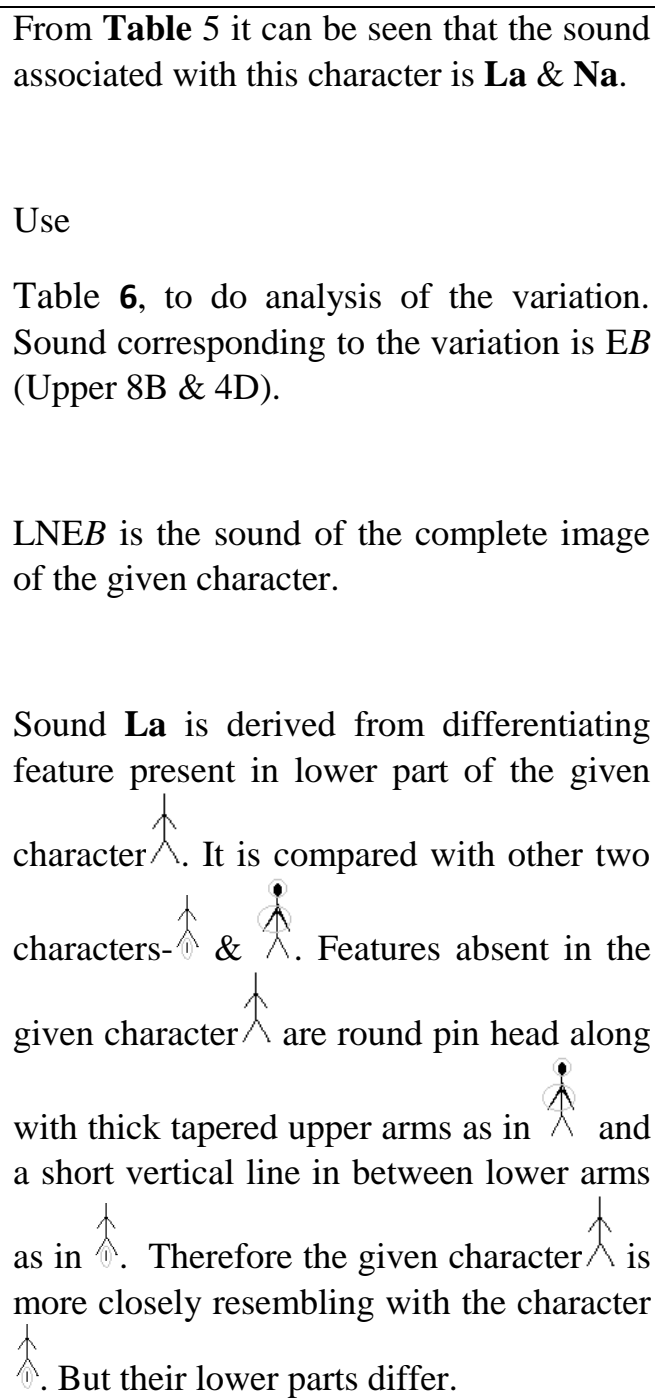 \\
\hline 6 & 枍 & T.S $\overbrace{80}$ & $\begin{array}{l}\text { Sound is LaNaTHa- } \\
\text { OoEVa for this } \\
\text { orientation. "a" suffixed } \\
\text { to all letters in upper } \\
\text { case is pronounced as in } \\
\text { "similar", but is } \\
\text { relatively short and } \\
\text { silent. }\end{array}$ & $\begin{array}{l}\text { From Table } 5 \text { it can be seen that the } \\
\text { sounds associated with this character are } \\
\text { La, Na, THa \& Oo. } \\
\text { Use } \\
\text { Table 6, to do analysis of the variation. } \\
\text { Sound corresponding to the variation is } \mathbf{E V}\end{array}$ \\
\hline
\end{tabular}




\begin{tabular}{|c|c|c|c|c|}
\hline $\begin{array}{l}\text { S. } \\
\text { No. }\end{array}$ & $\begin{array}{l}\text { CHAR- } \\
\text { ACTER }\end{array}$ & $\begin{array}{l}\text { CHARACTER } \quad \text { WITH } \\
\text { ARROWS FOR B \& D*. }\end{array}$ & $\begin{array}{l}\text { DERIVED } \\
\text { CHARACTER SOUND }\end{array}$ & $\begin{array}{llll}\text { PROCESS } & \text { OF } & \text { DERIVATION } & \text { OF } \\
\text { SOUND } & & & \end{array}$ \\
\hline & & $\begin{array}{l}\text { The only available } D \text { for } \\
8 \mathrm{~B} \text { in upper part is in fact } \\
6 \mathrm{D} \text {. It is clarified in } \\
\text { Table } 6 . \\
\text { As segment } \mathrm{C} \text { moves to a } \\
\text { new position on left side } \\
\text { (T.S), the centre of } \\
\text { depression or vertex of the } \\
\text { angle formed by segments } \\
\text { A \& C faces point } 6 \\
\text { (marked by lighter line) } \\
\text { instead of } 5 \text {. }\end{array}$ & & $\begin{array}{l}\text { (Upper 8B \& 6D). } \\
\text { LNTH-OoEV is the sound of the complete } \\
\text { structure of the character structure. } \\
\text { Sound TH-Oo (thu) is derived from } \\
\text { following differentiating features (circled) } \\
\text { of the given character } \\
\text { character differs from other two characters- } \\
\text { X } \text { X. The given character } \\
\text { curvy upper plate, when compared to this } \\
\text { character- } X \text {. The given character also } \\
\text { lacks space between lower part of the curve } \\
\text { and the point of origin of two short oblique } \\
\text { lines from the upper part of central axial } \\
\text { line, when compared to this character- } \\
\text { The character } \\
\text { with the given character } \\
\text { curvatures of their upper plates vary. }\end{array}$ \\
\hline 7 & 六 & T.S ${ }_{8 D}^{110}{ }_{5 B}^{2 B}$ L.S & $\begin{array}{l}\text { Sound is LaNaBa for this } \\
\text { orientation. "a" suffixed } \\
\text { to all letters in upper } \\
\text { case is pronounced as in } \\
\text { "similar", but is } \\
\text { relatively short and } \\
\text { silent. }\end{array}$ & 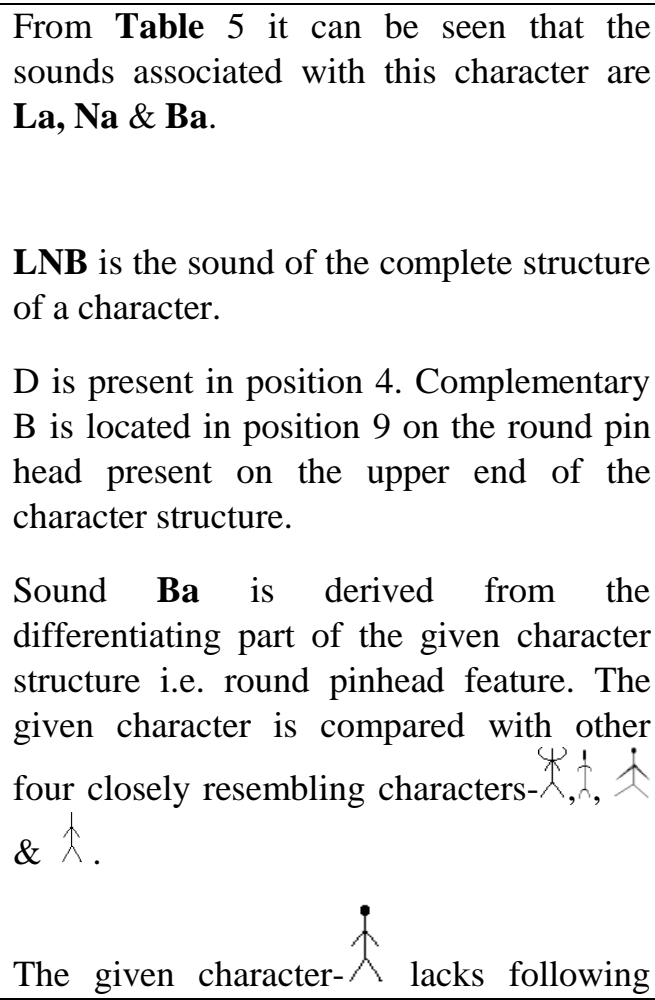 \\
\hline
\end{tabular}




\begin{tabular}{|c|c|c|c|c|}
\hline $\begin{array}{l}\text { S. } \\
\text { No. }\end{array}$ & $\begin{array}{l}\text { CHAR- } \\
\text { ACTER }\end{array}$ & $\begin{array}{l}\text { CHARACTER } \quad \text { WITH } \\
\text { ARROWS FOR B \& D*. }\end{array}$ & $\begin{array}{l}\text { DERIVED } \\
\text { CHARACTER SOUND }\end{array}$ & $\begin{array}{llll}\text { PROCESS } & \text { OF } & \text { DERIVATION } & \text { OF } \\
\text { SOUND } & & & \end{array}$ \\
\hline & & & & $\begin{array}{l}\text { features:- (a) curved upper plates as in the } \\
\text { character - (b) curved arms as in the } \\
\text { character - and (c) thick tapered upper } \\
\text { arms as in the character - The } \\
\text { character closely resembles with the } \\
\text { given character } 大 \text {, but it lacks round } \\
\text { pinhead. The differentiating part i.e., the } \\
\text { round pinhead feature of the given } \\
\text { character } 大 \text {, which is considered for } \\
\text { deriving the sound Ba. }\end{array}$ \\
\hline
\end{tabular}

\section{* Left side of each image is throat side \& right side is towards lip side.}

All images are created using Microsoft Paint without missing anything relevant. Table of standard script codes are provided for characters to be compared with that depicted in original site ${ }^{8}$.

NFM-Indus Script Unicode PUA table of codes of characters listed above ${ }^{8}$ :

\begin{tabular}{|c|c|c|c|c|c|c|c|}
\hline NFM & PUA CODES & S.No. & PUA CODES & & PUA CODES & & PUA CODES \\
\hline 1 & E3E-8 & 5 & E06-E & )+( & E2B-6 & 小 & E06F \\
\hline 2 & E5A-E & 6 & E04-5 & 小 & E2B-4 & 我 & E04-4 \\
\hline 3 & E44-3 & 7 & E06-C & $\bar{\lambda}$ & E06C & 亲 & E04-6 \\
\hline 4 & E2B-5 & & & & & & \\
\hline
\end{tabular}

S.No. - Serial number of the character in the table ${ }^{\mathrm{II}}$ provided in the official website mentioned below.

PUA CODE- Private use area code, NFM-National Fund for Mohenjodaro(Project) ${ }^{11}$

Table 8 - Sounds derived for some characters of Oracle Bone Script

\begin{tabular}{|c|c|c|c|c|}
\hline $\begin{array}{l}\text { S. } \\
\text { No. }\end{array}$ & $\begin{array}{l}\text { CHA } \\
\text { RAC } \\
\text { TER }\end{array}$ & $\begin{array}{lr}\text { CHARACTER } & \text { WITH } \\
\text { ARROWS FOR B \& D* }\end{array}$ & $\begin{array}{l}\text { DERIVED } \\
\text { SOUND }\end{array}$ & $\begin{array}{l}\text { PROCESS OF DERIVATION OF } \\
\text { RELATED SOUND }\end{array}$ \\
\hline 1. & $\psi$ & $\begin{array}{l}\text { T.S }{ }_{8 B}^{50} \text { L.S } \\
\text { 5D's present in upper } \\
\text { and lower parts of the } \\
\text { character is in fact } 6 \mathrm{D} \& \\
4 \mathrm{D} \text { respectively. It is } \\
\text { clarified in }\end{array}$ & $\begin{array}{l}\text { Sound is } \mathrm{RaCHaOoEVa} \text { for this } \\
\text { orientation. "a" suffixed to all } \\
\text { letters in upper case is } \\
\text { pronounced as in "similar", but is } \\
\text { relatively short and silent. } \\
\mathbf{R C H} \text { (as in "Archery") is derived } \\
\text { from the differentiating part of } \\
\text { the character. }\end{array}$ & $\begin{array}{l}\text { From Table } 5 \text { it can be seen that the } \\
\text { sound associated with this character } \\
\text { is Oo. } \\
\text { Use } \\
\text { Table 6, do analysis of the variations. } \\
\text { The resultant sounds are } \\
\text { RCH (Lower 8B \& 4D) \& EV } \\
\text { (Upper 8B \& 4D). } \\
\text { RCHOoEV is the sound of the } \\
\text { complete structure of the character. }\end{array}$ \\
\hline
\end{tabular}




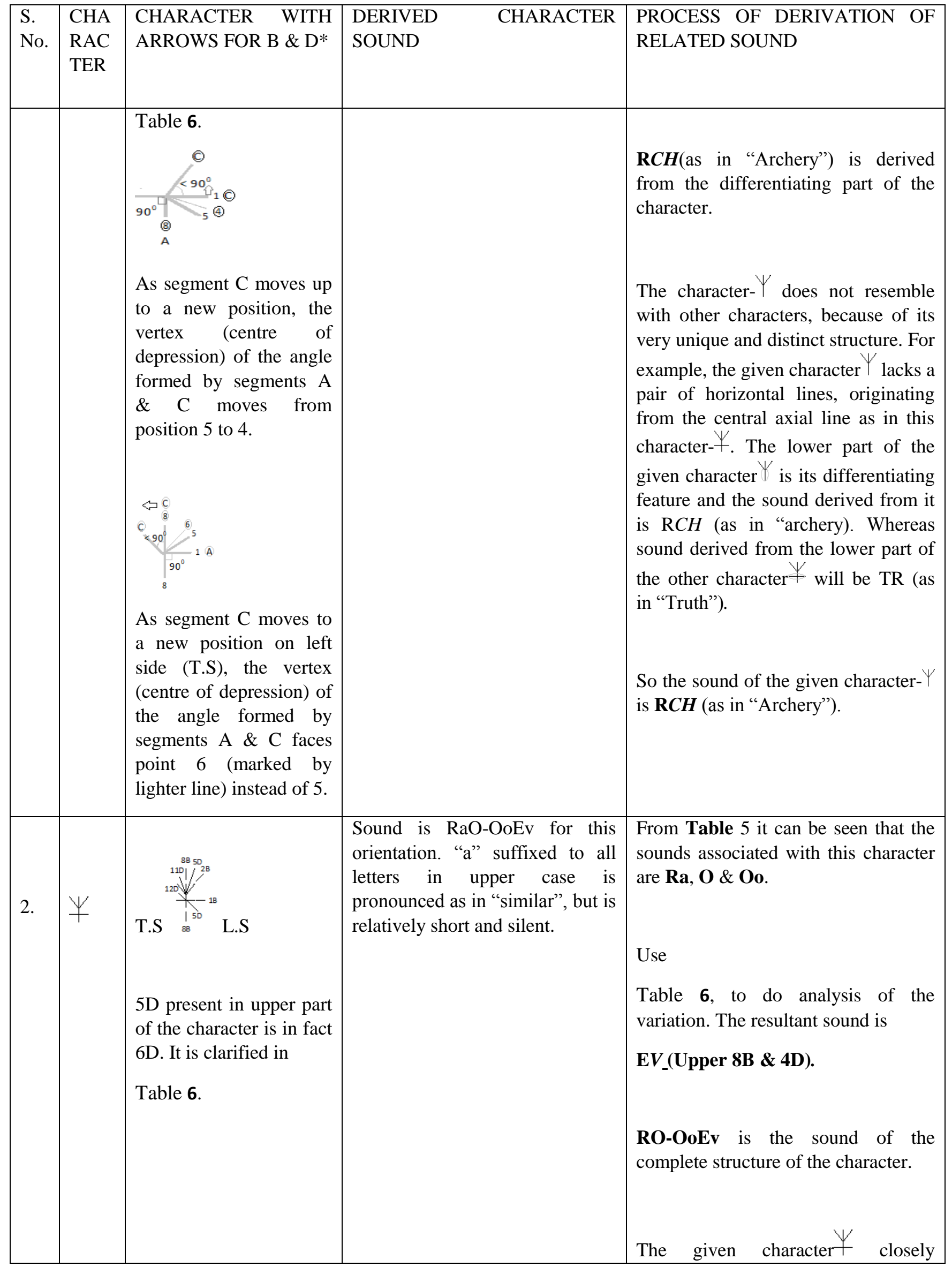




\begin{tabular}{|c|c|c|c|c|}
\hline $\begin{array}{l}\text { S. } \\
\text { No. }\end{array}$ & $\begin{array}{l}\text { CHA } \\
\text { RAC } \\
\text { TER }\end{array}$ & $\begin{array}{l}\text { CHARACTER WITH } \\
\text { ARROWS FOR B \& D* }\end{array}$ & $\begin{array}{l}\text { DERIVED } \\
\text { SOUND }\end{array}$ & $\begin{array}{l}\text { PROCESS OF DERIVATION OF } \\
\text { RELATED SOUND }\end{array}$ \\
\hline & & $\begin{array}{l}\text { As segment C moves to } \\
\text { a new position on upper } \\
\text { left side (T.S), the vertex } \\
\text { (centre of depression) of } \\
\text { the angle formed by } \\
\text { segments A \& C faces } \\
\text { point } 6 \text { (marked by } \\
\text { lighter line) instead of } 5 .\end{array}$ & & $\begin{array}{l}\text { resembles with the character- } \Psi \text {. The } \\
\text { differentiating part (circled) of the } \\
\text { given character consists of a pair of } \\
\text { horizontal lines }(\Psi) \text { originating from } \\
\text { both sides of a central axial line } \\
\text { instead of two oblique lines as in the } \\
\text { character } \Psi \text {. Sound of the given } \\
\text { character } \Psi \text { is } \mathbf{O} \text { derived from the } \\
\text { differentiating part i.e., a horizontal } \\
\text { line. }\end{array}$ \\
\hline 3 & $T$ & T.S $\left.\right|_{8 B} ^{-18}$ L.S & $\begin{array}{l}\text { Sound is TaRa for this } \\
\text { orientation. } \\
\text { "a" suffixed to all letters in upper } \\
\text { case is pronounced as in } \\
\text { "similar", but is relatively short } \\
\text { and silent. }\end{array}$ & $\begin{array}{l}\text { From Table } 5 \text { it can be seen that the } \\
\text { sounds associated with this character } \\
\text { are Ta, \& Ra. } \\
\text { TR is the sound of the complete } \\
\text { structure of the character. } \\
\text { The given character } \mathrm{T} \text { is compared } \\
\text { with this character- }- \text {. The only } \\
\text { differentiating feature (circled) is lack } \\
\text { of a short horizontal line above as in } \\
\text { the given character- } \mathrm{T} \text {. So, the sound } \\
\text { of the given character is } \mathbf{T} \text {, as it is } \\
\text { derived from the differentiating part } \\
\text { i.e., the lone upper horizontal line } \\
\text { present in the upper part of the } \\
\text { character structure. }\end{array}$ \\
\hline 4. & L & T.S $\square$ L.S & $\begin{array}{l}\text { Sound is E for this orientation. } \\
\text { "a" suffixed to all letters in upper } \\
\text { case is pronounced as in } \\
\text { "similar", but is relatively short } \\
\text { and silent. }\end{array}$ & $\begin{array}{l}\text { From Table } 5 \text { it can be seen that the } \\
\text { sound associated with this character } \\
\text { is } \mathbf{E} \text {. } \\
\mathrm{E} \text { is the sound of the complete } \\
\text { structure of the character. } \\
\text { The given characters is compared } \\
\text { with following characters- } U+H \text {. } \\
\text { Features that differentiate the given } \\
\text { character- } \sqcup \text { from other characters are }\end{array}$ \\
\hline
\end{tabular}




\begin{tabular}{|c|c|c|c|c|}
\hline $\begin{array}{l}\text { S. } \\
\text { No. }\end{array}$ & $\begin{array}{l}\text { CHA } \\
\text { RAC } \\
\text { TER }\end{array}$ & $\begin{array}{l}\text { CHARACTER WITH } \\
\text { ARROWS FOR B \& D* }\end{array}$ & $\begin{array}{l}\text { DERIVED } \quad \text { CHARACTER } \\
\text { SOUND }\end{array}$ & $\begin{array}{l}\text { PROCESS OF DERIVATION OF } \\
\text { RELATED SOUND }\end{array}$ \\
\hline & & & & $\begin{array}{l}\text { lack of a tapered lower part as in the } \\
\text { character- } U \text { as well as two short } \\
\text { horizontal lines jutting out on both } \\
\text { sides along with four short vertical } \\
\text { lines in excess as in the Character-+1 } \\
\text { So, the sound of the given } \\
\text { character is E, which is derived } \\
\text { from its differentiating part i.e., sharp } \\
\text { right angled corners of the base. }\end{array}$ \\
\hline
\end{tabular}

* Left side of each image is throat side \& right side is towards lip side

All images are created using Microsoft Paint without missing anything relevant. Table of standard character codes are provided for characters to be compared with that depicted in original site?

CODES OF ORACLE BONE SCRIPTS LISTED IN TABLE $8^{9}$ :

\begin{tabular}{|l|l|l|l|l|l|l|l|l|}
\hline $\begin{array}{l}\text { S.No. in } \\
\text { table no. }\end{array}$ & S.No. & I.D & $\begin{array}{l}\text { SOURCE } \\
\text { No. }\end{array}$ & $\begin{array}{l}\text { S.No. in table } \\
\text { no. }\end{array}$ & S.No. & I.D & SOURCE No. \\
\hline 1 & 203 & G00134 & A-27218 & & $\Psi$ & 936 & T00575 & A-27075 \\
\hline 2 & 935 & G00658 & A-28059 & & $\bar{T}$ & 47 & G00041 & A-01252 \\
\hline 3 & 46 & T00044 & A-00021-1 & & & 985 & G00702 & A-03936-1 \\
\hline 4 & 986 & T00765 & A-21249 & H+ & 987 & G00704 & A-00907-1 \\
\hline
\end{tabular}

S.No.in table no. - Serial number of the character in the table 8.

S.No. - Serial number of the character in the report cited below.

I.D-Identification number of the character in the report cited below.

Source No.-Numbers allotted to sources of characters presented in the report cited below.

Reference Report : ISO/IEC JTC1/SC2/WG2 N4687, DATED-21-10-2015, TITLE: Request for comment on encoding Oracle bone script. SOURCE:TCA and China

\section{Discussion}

\subsection{EGYPTIAN HIEROGLYPHS}

Refer to Table 3 which contains 5 characters selected for analysis along with their derived sounds.

1. $\mathbf{T} a$ is the sound of the image differentiators of related glyph $\bigcirc$. The image of the character can be reproduced using bulges and depressions associated with the sound $\mathbf{T} a$. The tongue tip movements trace the differentiating part of the glyph. Bulge (1B) and depression (12D) associated with Ta is at approximately $\mathbf{0}^{\mathbf{0}} \& \mathbf{1 3 5}^{\mathbf{0}}$ respectively, within the lower half of the vocal circle (Up.V.C).

Positions of points $1 \& \mathbf{1 2}$ in upper half of the vocal circle (Up.V.C) are located at approximately $\mathbf{0}^{\mathbf{0}} \& \mathbf{1 3 5}^{\mathbf{0}}$ respectively.

Therefore, bulge (12B) and depression (1D) associated with TH $a$ will be at approximately $\mathbf{1 3 5}^{0} \& \quad \mathbf{0}^{0}$ respectively, within the lower half of vocal circle (Up.V.C).

2. $\mathbf{R} a$ is the sound of the image differentiators of related glyph $\longleftrightarrow$. The image of the character can be reproduced using bulges and depressions associated with the sound $\mathbf{R} a$.

The tongue tip movements trace the differentiating part of the glyph. Bulge (8B) and depression (5D) associated with $\mathrm{Ra}$ is at approximately $\mathbf{9 0}^{\mathbf{0}} \& \mathbf{4 5}^{\mathbf{0}}$ respectively, within the lower half of the vocal circle (Up.V.C).

Positions of points $8 \& \mathbf{5}$ in upper half of the vocal circle (Up.V.C) are located at approximately $\mathbf{9 0}^{\mathbf{0}} \& \mathbf{4 5}^{\mathbf{0}}$ respectively. 
3. $\mathbf{L} a$ is the sound of the image differentiators of related glyph $=$. The image of the character can be reproduced using bulges and depressions associated with the sound $\mathbf{L} a$. The tongue tip movements trace the differentiating part of the glyph. The tongue tip movements trace the differentiating part of the glyph. Bulge (5B) and depression (8D) associated with $\mathrm{La}$ is at approximately $45^{\circ} \& 90^{\circ}$ respectively, within the lower half of the vocal circle (Up.V.C).

4. $\mathbf{K} a$ is the sound of the image differentiators of related glyph $\square$. The image of the character can be reproduced using bulges and depressions associated with the sound $\mathbf{K} a$. The tongue tip movements trace the differentiating part of the glyph. The tongue tip movements trace the differentiating part of the glyph. Bulge (5B) and depression $(\mathbf{8 D})$ associated with $\mathrm{Ka}$ is at approximately $\mathbf{4 5}^{\circ} \& \mathbf{9 0}^{\mathbf{0}}$ respectively, within the upper half of the vocal circle (Lw.V.C).

Positions of points $8 \& 5$ in upper half of the vocal circle (Lw.V.C) are located at approximately $90^{\mathbf{0}} \& \mathbf{4 5}^{\mathbf{0}}$ respectively. Therefore, bulge $(\mathbf{8 B})$ and depression $(5 \mathrm{D})$ associated with $\mathbf{E}$ will be at approximately $\mathbf{9 0}^{\mathbf{0}} \& \mathbf{4 5}^{\mathbf{0}}$ respectively, within the upper half of the vocal circle (Lw.V.C).

5. PH $a$ is the sound of the image differentiators of related glyph $\square$. The image of the character can be reproduced using bulges and depressions associated with the sound $\mathbf{P H} a$. The tongue tip movements trace the differentiating part of the glyph. The tongue tip movements trace the differentiating part of the glyph. Bulge (12B) and depression (1D) associated with PHa is at approximately $135^{\mathbf{0}} \& \mathbf{0}^{\mathbf{0}}$ respectively, within the upper half of the vocal circle (Lw.V.C).

$\mathrm{PHa}$ is $\mathrm{Pa}$ with stress on Ha. It is not Fa.

Positions of points $1 \& \mathbf{1 2}$ in upper half of the vocal circle (Lw.V.C) are located at approximately $\mathbf{0}^{\mathbf{0}} \& \mathbf{1 3 5}^{\mathbf{0}}$ respectively. Position of point $\mathbf{1}\left(\mathbf{0}^{\mathbf{0}}\right)$ is shared by both, $\mathbf{P H} a \&$ TH $a$.

\subsection{Linear B Syllabary}

Refer to

Table 4 which contains 2 characters selected for analysis along with their derived sounds.

1. RO is the sound of the image differentiators of related glyph + . The image of the character can be reproduced using bulges and depressions associated with the sound RO. The tongue tip movements trace the differentiating part of the character. Bulge (8B) and depression (5D) associated with Ra is at approximately $90^{\circ} \& 45^{\circ}$ respectively within the lower half of the vocal circle (Up.V.C). Similarly, bulge (1B) and depression (12D) associated with $\mathbf{O}$ is at approximately $0^{0} \& 135^{\circ}$ respectively, within the upper half of the vocal circle (Lw.V.C).

2. TO is the sound of the image differentiators of related glyph $\mp$. The image of the character can be reproduced using bulges and depressions associated with the sound TO .The tongue tip movements trace the differentiating part of the character. Bulge (1B) and depression (12D) associated with Ta is at approximately $0^{0} \& 135^{\circ}$ respectively within the lower half of the vocal circle (Up.V.C). Similarly, bulge (1B) and depression (12D) associated with $\mathbf{O}$ is at approximately $0^{0} \& 135^{\circ}$ respectively within the upper half of the vocal circle (Lw.V.C).

3. Above discussed positions (Referred to as standard positions) of key points of unmixed sounds helps in identifying relative positions of rest of the unmixed sounds.

\subsection{Flow Chart for Identifying Sounds of Characters of Ancient Scripts}

Numbering of B \& D of a character is done from Upper left $\rightarrow$ Lower left in a clockwise manner. Derived sounds from each part of the character are added from Lower left $\rightarrow$ Upper left in an anti-clockwise manner. 


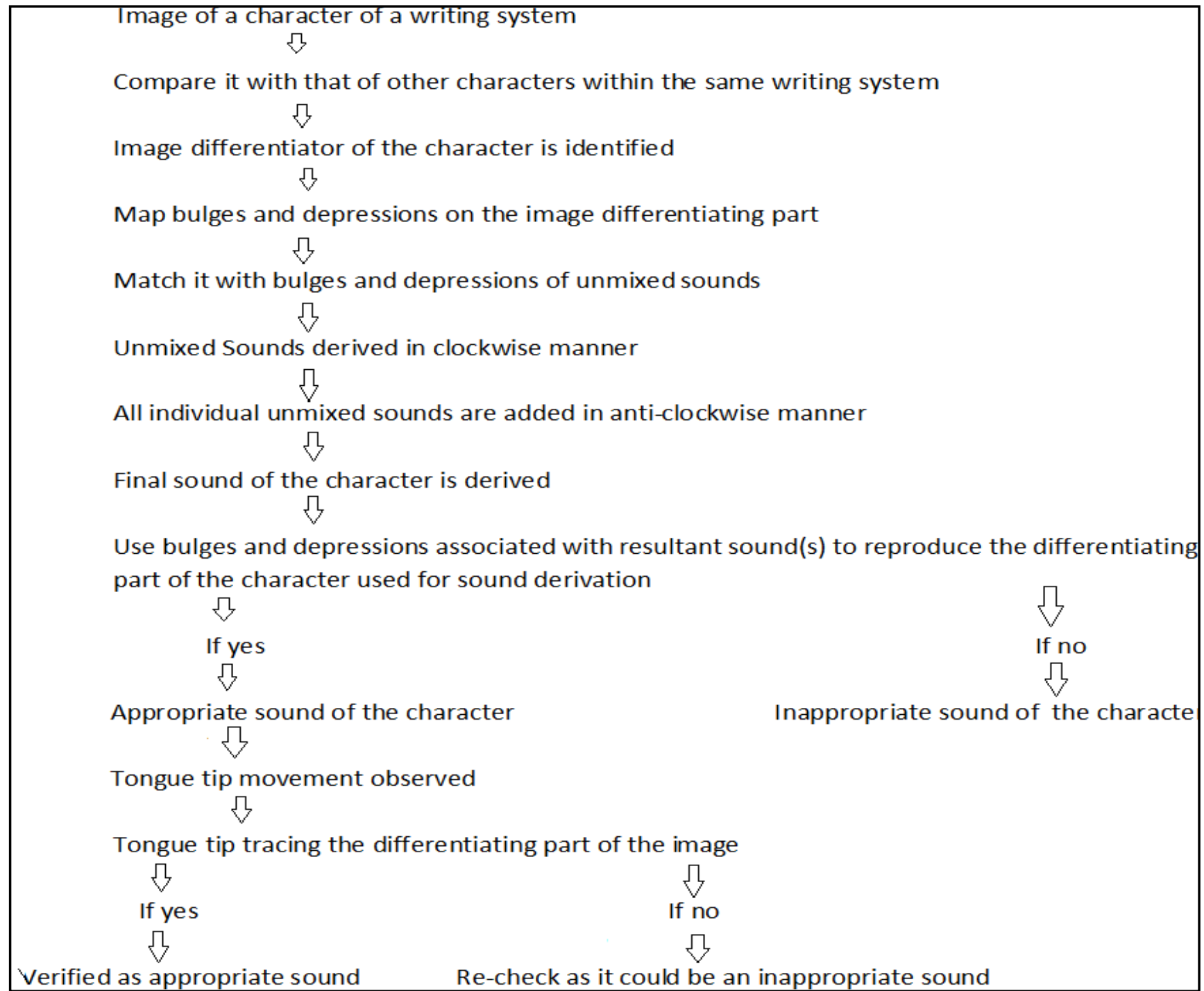

Note:

False positive sound: If image differentiator is incorrectly chosen, sounds too may turn out to be incorrect and the related tongue contours and tongue tip movements may trace the incorrect image differentiator.

Sound of image differentiator is part(s) is part of sounds derived from complete structure or image of a character because the image differentiator is a part of the complete structure of the character.

Sound derived from a complete image of a character may not be the sound used by the people of that civilization.

\subsection{Identification of Sounds of Some Characters from Indus Valley Script}

Refer to Table 7 which contains 7 characters selected for analysis along with their derived sounds.

Sounds represented by suffixed letters in italics are not dominant sounds.

1. $\mathrm{L} a$ is identified as the sound of this complete character structure- $\wedge$ using tongue contours. The image of the character can be reproduced using bulges and depressions associated with the sound La. On verbalizing La, the tongue tip movement traces image of the given character. Sound of the character is $\mathbf{L} \boldsymbol{a}$.

2. $\mathrm{Ka}$ is identified as the sound of this complete character structure- $\vee$ using tongue contours. The image of the character can be reproduced using bulges and depressions associated with the sound $\mathbf{K} \boldsymbol{a}$. On verbalizing $\mathbf{K} \boldsymbol{a}$, the tongue tip movement traces image of the given character. Sound of the character is Ka.

3. LEBa is identified as identified as the sound of this complete character structure- $\lambda$ using tongue contours. On verbalizing LEb, the tongue tip movement traces image of the given character. Sound of the character is Eb, which is derived from the differentiating part of the given character. 
4. The differentiating part of the image of the character used for analysis can be reproduced using bulges and depressions associated with the sound $\mathbf{E} \boldsymbol{b}$.On verbalizing $\mathrm{Eb}$, the tongue movement traces differentiating part of image (circled part) of the given character- $\wedge$.

5. NaRaMaEBa (NRmEb) is identified as the sound of this complete character structure- $\uparrow$ using tongue contours. On verbalizing $\mathrm{NRmEb}$, the tongue tip movement traces image of the given character. Sound of the character is $\mathrm{Rm}$ is derived from the differentiating part of the given character. The differentiating part of the image of the character used for analysis can be reproduced using bulges and depressions associated with the sound $\mathbf{R} \boldsymbol{m}$. On verbalizing $\mathrm{Rm}$, the tongue tip movement traces differentiating part of image (circled part) of the given character- $\uparrow$.

6. LNEB is identified as the sound of the complete character structure- $\lambda$ using tongue contours. On verbalizing $\mathrm{LNE} B$, the tongue tip movement traces image of the given character. Sound of the character is $\mathbf{L} \boldsymbol{a}$ is derived from the differentiating part of the given character. The differentiating part of the image of the character used for analysis can be reproduced using bulges and depressions associated with the sound $\mathbf{L} \boldsymbol{a}$. On verbalizing $\mathbf{L} \boldsymbol{a}$, the tongue tip movement traces differentiating part of image (circled part) of the given character- ${ }^{\wedge}$. $L a$ is also the sound of the character $-\wedge$. Therefore, character $\wedge$ could have substituted this character. It might have might have evolved from the character- $\lambda$.

7. $\mathrm{L} a \mathrm{~N} a \mathrm{TH} a \mathrm{OoEV} a$ is identified as the sound of the complete character structure- $\mathrm{x}$ using tongue contours. On verbalizing $\mathrm{LNTHOoEV}$, the tongue tip movement traces image of the given character. Sound of the character is THOo is derived from the differentiating part of the given character. The differentiating part of the image of the character used for analysis can be reproduced using bulges and depressions associated with the sound THOo. On verbalizing THOo, the tongue tip movement traces differentiating part of image (circled part) of the given character- $\AA$.

8. $\mathrm{L} a \mathrm{NaB} a$ is identified as the sound of the complete character structure- $\AA$ using tongue contours. On verbalizing $\mathrm{LNB}$, the tongue tip movement traces image of the given character. Sound of the character is $\mathbf{B} \boldsymbol{a}$ is derived from the differentiating part of the given character. The differentiating part of the image of the character used for analysis can be reproduced using bulges and depressions associated with the sound $\mathbf{B} \boldsymbol{a}$. On verbalizing $\mathbf{B} \boldsymbol{a}$, the tongue tip movement traces differentiating part of image (circled part) of the given character- $\mathrm{A}$.

Note: Characters, (1) \& (5) of Indus valley script bear the same sound value, "La". So character (1) could be the symbolic version of the character (5), which may be easier to write. Character (1) could have evolved from character (5). The sound \& structure of a character may get shortened as well as simplified with passage of time as observed in case of character (1) \& (5) of Indus script. But alterations of its orientations have not been observed in cases of characters (1) \& (5) as they have yielded similar sound La.

\subsection{Derivation of Sounds of Some Characters from Oracle Bone Script}

Refer to Table 8 which contains 4 characters selected for analysis along with their derived sounds.

1. $\mathrm{RCH} a \mathrm{OoEV} a$ is identified as the sound of the complete character structure- $\Psi$ using tongue contours. The differentiating part of the image of the character used for analysis can be reproduced using bulges and depressions associated with the sound $\mathbf{R C H}$. On verbalizing $\mathrm{RCHOoEV}$, the tongue movement traces image of the given character. The sound of this character is $\mathbf{R} \boldsymbol{C H}$. On verbalizing $\mathbf{R} \boldsymbol{C H}$, the tongue movement traces differentiating part of image (circled part) of the given character- $\psi$.

2. RaO-OoEva is identified as the sound of the complete character structure- $\psi$ using tongue contours. On verbalizing ROOoEv, the tongue tip movement traces image of the given character. The sound of this character is $\mathrm{O}$ is derived from the differentiating part of the given character. The differentiating part of the image of the character used for analysis can be reproduced using bulges and depressions associated with the sound O. On verbalizing $\mathrm{O}$, the tongue tip movement traces differentiating part of image (circled part) of the given character- $\frac{Y}{}$. 
3. TaR $a$ is identified as the sound of the complete character structure- $T$ using tongue contours. On verbalizing TR, the tongue tip movement traces image of the given character. The sound of this character is $\mathbf{T} \boldsymbol{a}$ is derived from the differentiating part of the given character. Character structure \& sound of $T$ is closely resembles English alphabet " $\mathrm{T}$. The differentiating part of the image of the character used for analysis can be reproduced using bulges and depressions associated with the sound $\mathbf{O}$. On verbalizing $\mathbf{T} \boldsymbol{a}$, the tongue tip movement traces differentiating part of image (circled part) of the given character- $T$.

4. $\quad \mathrm{E}$ is identified as the sound of the complete character structure- $\sqcup$ using tongue contours. On verbalizing E, the tongue tip movement traces image of the given character. The sound of this character is $\mathbf{E}$ is derived from the differentiating part of the given character. The part of the image of the character used for analysis can be reproduced using bulges and depressions associated with the sound $\mathbf{E}$. On verbalizing $\mathbf{E}$, the tongue movement traces differentiating part of image (circled part) of the given character- ! !

\section{Conclusion}

This work confirms that there is a relation between images of ancient script characters, their sounds, related tongue tip movements and tongue contours. Once the relation was established, it was used to identify sounds of characters of ancient scripts (Indus Valley and Oracle Bone Script). So, this approach may be of help in identifying sounds of ancient scripts representing images and as well as understanding primitive spoken languages lacking written scripts.

\section{References}

Egyptian Hieroglyphs[PDF file]. (n.d.). Retrieved from https://unicode.org/charts/PDF/U13000.pdf

Gardiner, A. H. (1957). "Sect. X. Loaves and Cakes". In Egyptian grammar: Being an introduction to the study of hieroglyphs (3rd ed.)(pp 531). London: Published on behalf of the Griffith Institute, Ashmolean Museum, Oxford, by Oxford University Press.

Gardiner, A. H. (1957). "Sect. D. Parts of the Human Body". In Egyptian grammar: Being an introduction to the study of hieroglyphs (3rd ed.)(pp 452). London: Published on behalf of the Griffith Institute, Ashmolean Museum, Oxford, by Oxford University Press.

Gardiner, A. H. (1957). "Sect. E. Mammals". In Egyptian grammar: Being an introduction to the study of hieroglyphs (3rd ed.)(pp 460). London: Published on behalf of the Griffith Institute, Ashmolean Museum, Oxford, by Oxford University Press.

Gardiner, A. H. (1957). “Sect. V. Rope, Fibre, Baskets, Bags, etc.”. In Egyptian grammar: Being an introduction to the study of hieroglyphs (3rd ed.)(pp 525). London: Published on behalf of the Griffith Institute, Ashmolean Museum, Oxford, by Oxford University Press.

Gardiner, A. H. (1957). "Sect. Q. Domestic and Funerary Furniture". In Egyptian grammar: Being an introduction to the study of hieroglyphs (3rd ed.)(pp 500). London: Published on behalf of the Griffith Institute, Ashmolean Museum, Oxford, by Oxford University Press.

Linear B Syllabary[PDF file]. (n.d.). Retrieved from https://www.unicode.org/charts/PDF/U10000.pdf

NFM-Indus Script Unicode PUA table of codes.(n.d.). National Fund for Mohenjodaro. Retrieved from http://mohenjodaroonline.net/index.php/indus-script/table-of-pua-codes

Request for comment on encoding Oracle Bone Script (L2/15-280)[PDF file].(2015). Retrieved from https://www.unicode.org/L2/L2015/15280-n4687-oracle-bone.pdf

Stein, Gil. (2015). Foreword. In Christopher Woods-Geoff Emberling-Emily Teeter (Ed.). Visible language: inventions of writing in the ancient Middle East and beyond (pp. 7). Oriental Institute of the University of Chicago. Retrieved from https://oi.uchicago.edu/research/publications/oimp/oimp-32-visible-language-inventionswriting-ancient-middle-east-and

The Life of Michael Ventris.(n.d.). University of Cambridge. Retrieved from https://www.classics.cam.ac.uk/research/projects/mycep/decipherment/ventris

Timeline. (n.d.). Retrieved October 10, 2019, from http://www.ancientscripts.com/ws_timeline.html

Weissbach, M. M. (2000). Jean François Champollion and the True Story of Egypt [PDF]. 21St Century Science and Technology. 12 (4): 26-39. Retrieved from http://21sci-tech.com/articles/Spring03/Champollion.pdf 